*ak RMIS View/Frint Document Cover Sheet tow

This document was retrieved from the Documentation and Records Management (DRM) ISEARCH System. It is intended for Information only and may not be the most recent or updated version. Contact a Document Service Center (see Hanford Info for locations) if you need additional retrieval information.

Accession \#: D196052055

Document \#: SD-WM-ES-377

Title/Desc:

OPERATIONAL TANK LEAK DETECTION \& MINIMIZATION DURING RETRIEVAL

Pages: 60 

2. To: (Receiving Organization)
GA Meyer Retrieval Programs
5. Proj./Prog./Dept./Div.:
Waste Management
6. Cog. Engr.:
D. F. Iwatate

8. Originator Remarks:

Initial transmittal for approval.

3. From: (Originating Organization)

Plant Systems Technical Basis

4. Related EDT No.:

7. Purchase Order No.:

$N / A$

9. Equip./Component No.:

$N / A$

10. System/Bldg./Facility:

$N / A$

11. Receiver Renarks:

12. Major Assm. Dwg. No.:

N/A

13. Permit/Permit Application No.: $N / A$

14. Required Response Date:

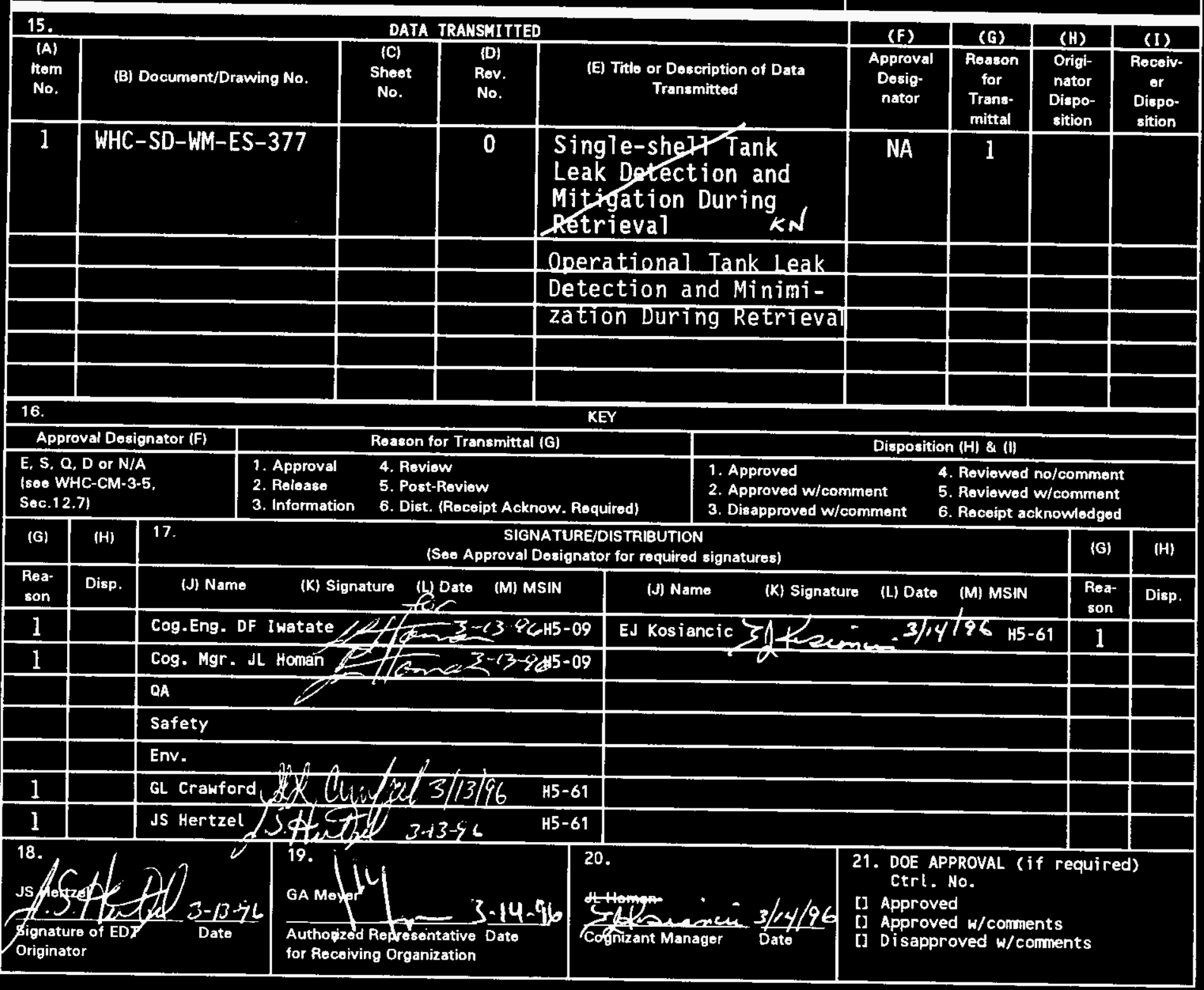

8D-7400-172-2(04/94) GEF097 


\title{
Operational Tank Leak Detection and Minimization During Retrieval
}

\author{
J. S. Hertzel
}

Westinghouse Hanford Company, Richland. WA 99352

U.S. Department of Energy Contract DE-AC06-87RL10930

$\begin{array}{lll}\text { EDT/ECN: } & 605652 & \text { UC: } 721 \\ \text { Org Code: } & 73530 & \text { Charge Code: } \\ \text { B\&R Code: } & \text { EW3130010 } & \text { Total Pages: } 57\end{array}$

Key Words: single-shell tank, waste, leak, detection

Abstract: This report evaluates the activities associated with the retrieval of wastes from the single-shell tanks proposed under the Initial single-Shell Tank Retrieval System. This report focuses on minimizing leakage during retrieval by using effective leak detection and mitigating actions. After reviewing the historical data available on single-shell leakage, and evaluating current leak detection technology, this report concludes that the only currently available leak detection method which can function within the most probable leakage range is the mass balance system. If utilized after each sluicing campaign, this mathod should allow detection at a leakage value well below the leakage value where significant heal th effects occur which is calculated for each tank. Furthermore, this report concludes that the planned sequence or sluicing activities will serve to further minimize the probability and volune of leaks by keeping liquid away from areas with the greatest potential for leaking.

Finally, this report identifies a series of operational responses which when used in conjunction with the recomended stuicing sequence and leak detection methods will minimize worker exposure and environmental safety health risks.

TRADEMARK DISCLAIMER. Reference herein to any specific commercial product, process, or service by trade name, trademark, manufacturer, or otherwise, does not necessarily constitute or imply its endorsenent, recomendation, or favoring by the United States Government or any agency thereof or its contractors or subcontractors.

Printed in the United states of America. To obtain copies of this document, contact: wHC/BCS Document Control Services, P.0. Box 1970, Mailstop H6-08, Richland WA 99352, Phone (509) 372-2420;
Fax (509) 376-4989.
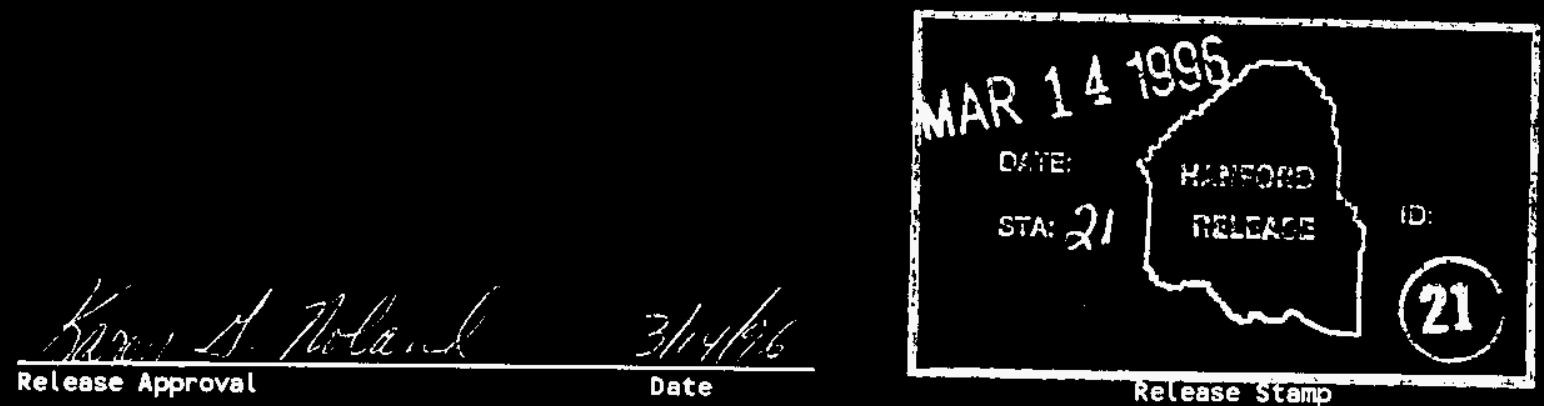

\section{Approved for Public Release}




\title{
OPERATIONAL TANK LEAK DETECTION AND MINIMIZATION DURING RETRIEVAL
}

March 11, 1996

\author{
Prepared for: \\ Westinghouse Hanford Company \\ Purchase Order MSJ-SBW-336070 \\ Task A96-126 \\ Report No. 951126-001 \\ Revision D
}

Prepared by: Richard J. Stuart

Bruce D. Groth

Thomas L. Pehl,

Approved by:

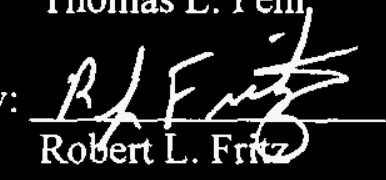

$3-11-96$

Date: 


\section{EXECUTIVE SUMMARY}

This report evaluates the activities associated with the retrieval of wastes from the single-shell tanks (SSTs) proposed under the Initial Single-Shell Tank Retrieval System (ISSTRS). This report focuses on operational methods of minimizing leakage during retrieval by using effective leak prevention, detection, and mitigating actions. After reviewing the historical data available on SST leakage (duration, size, rate, etc.) and evaluating current leak detection technology, this report concludes that the only currently available leak detection method which can detect a leak within a reasonable leakage volume and time frame is the mass balance system. Furthermore, this report concludes that the operational sequence of sluicing activities presented in this report will serve to further minimize the probability and volume of leaks by keeping liquid away from areas with the greatest potential for leaking.

Finally, this report identifies a series of operational responses which when used in conjunction with the recommended sluicing sequence and leak detection methods will minimize worker exposure and environmental, safety, and health risks. 


\section{TABLE OF CONTENTS}

\section{EXECUTIVE SUMMARY}

1.0 INTRODUCTION

\section{$1.1 \quad$ Background}

1.1.1 TPA Milestones $\ldots \ldots \ldots \ldots \ldots \ldots \ldots$

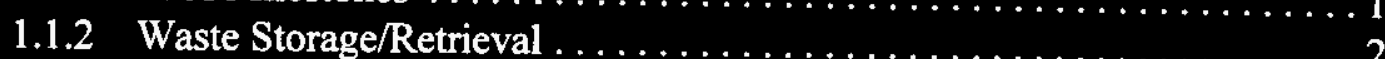

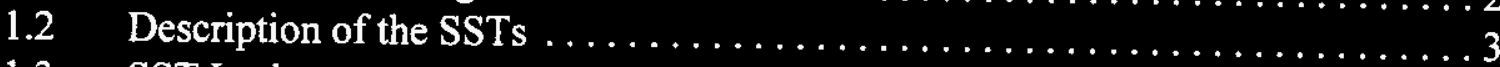

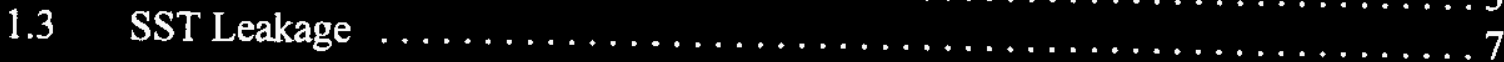

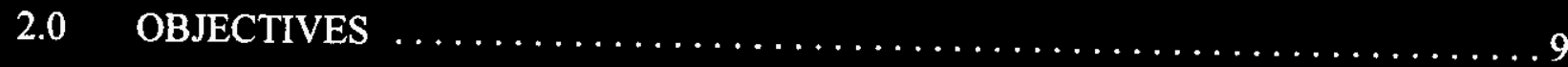

$3.0 \quad$ ISSTRS RETRIEVAL METHODOLOGY $\ldots \ldots \ldots \ldots \ldots \ldots \ldots \ldots \ldots \ldots$

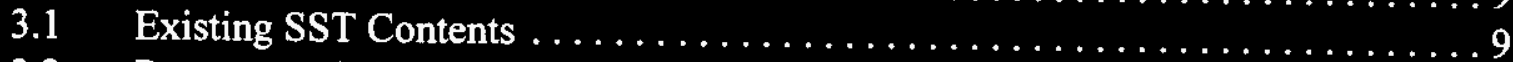

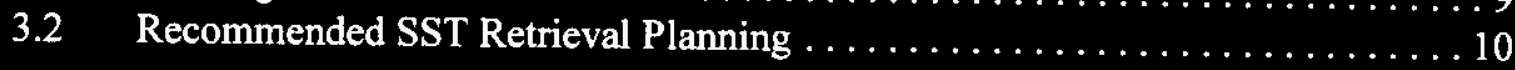

4.0 CURRENT AVAILABLE LEAK DETECTION TECHNOLOGY $\ldots \ldots \ldots \ldots \ldots, 14$

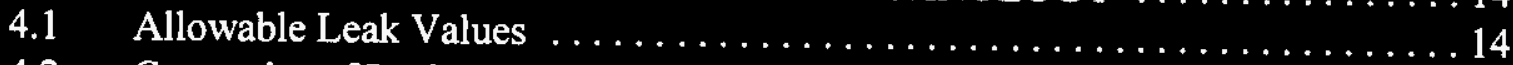

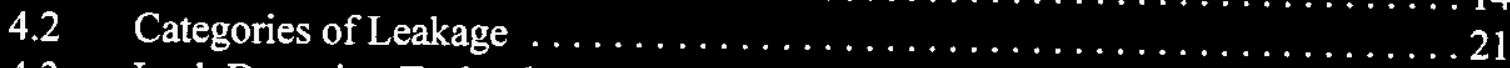

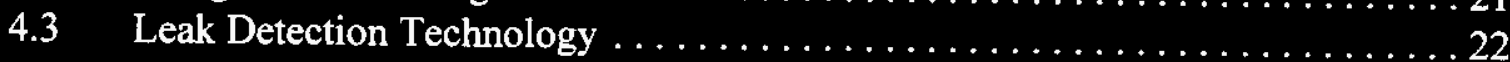

4.3.1 Mass Balances ................................ 23

4.3.1.1 Methods of Level Measurement . . . . . . . . . . . . . 24 24

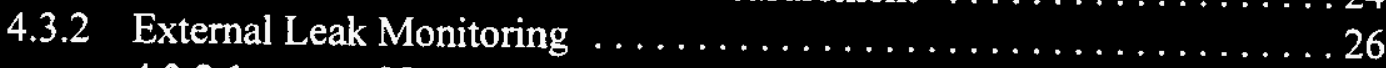

4.3.2.1 Neutron Logging of Drywells ............... 26

4.3.2.2 Passive Gamma Logging of Drywells . . . . . . . . . 27

4.3.2.3 Leak Detection Pits .................... 28

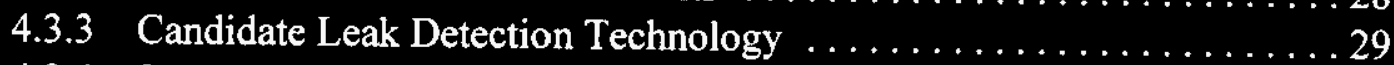

4.3.4 Summary and Conclusions $\ldots \ldots \ldots \ldots \ldots \ldots \ldots \ldots \ldots \ldots \ldots$

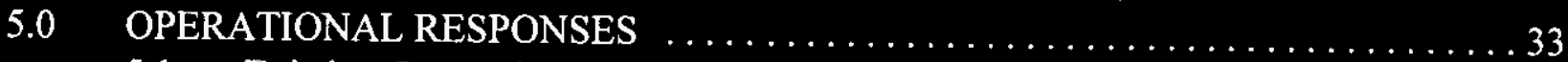

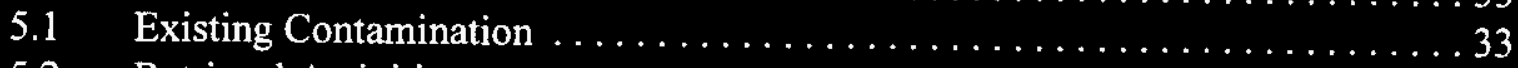

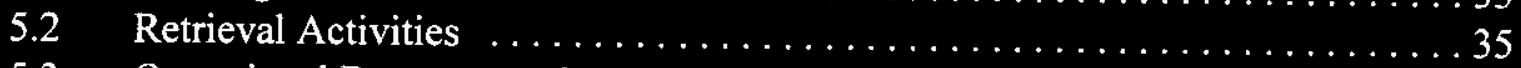

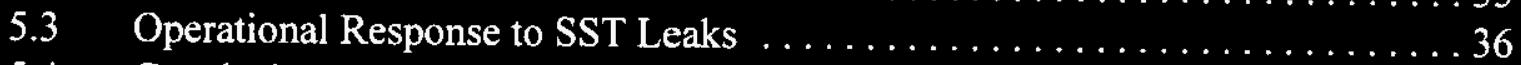

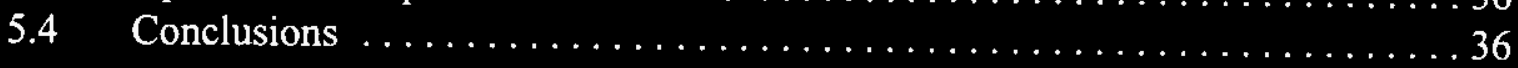

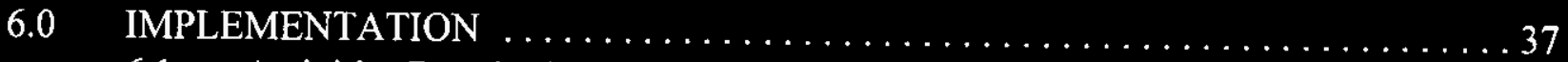

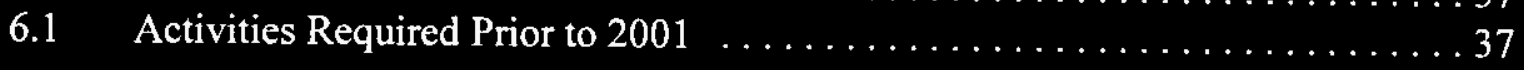




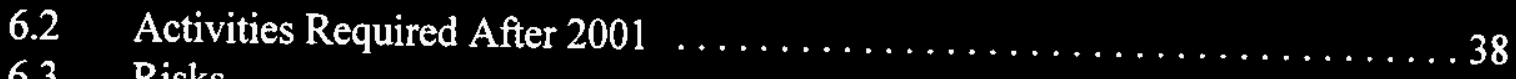

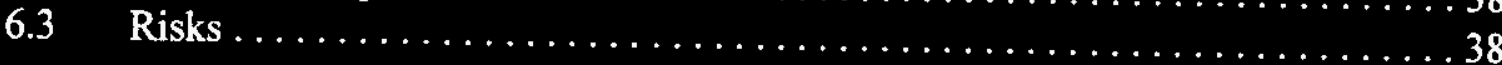

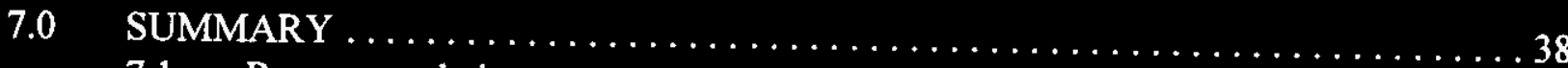

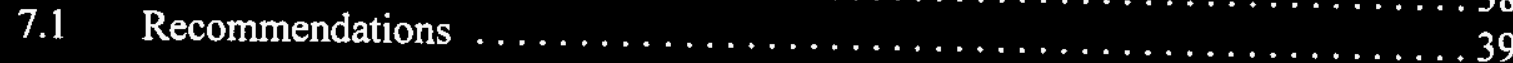

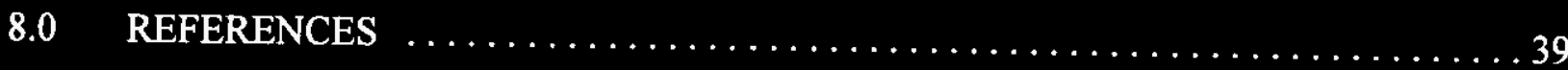

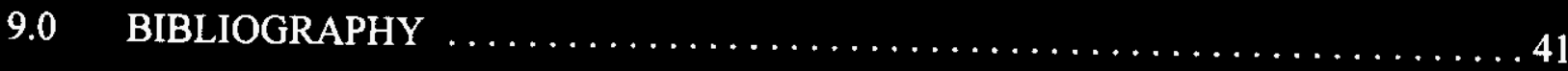

APPENDICES

Appendix A

Mass Balance for Leak Detection

Appendix B

A-1

Mass Balance Accuracy

Appendix C

B-1

ISSTRS Operational Leak Response 


\section{FIGURES}

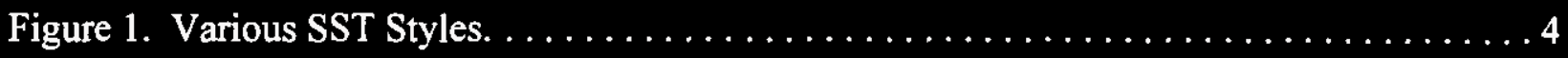

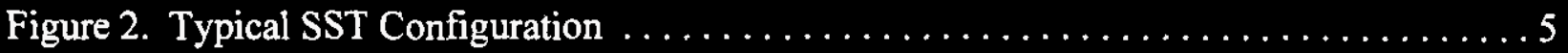

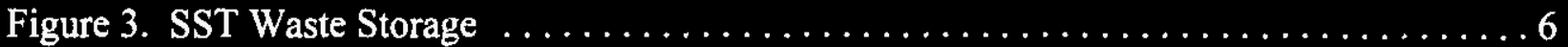

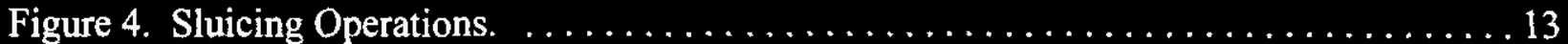

Figure 5. Preliminary SST Threshold Leakage Values $\ldots \ldots \ldots \ldots \ldots \ldots \ldots \ldots \ldots \ldots$

Figure 6. Categories of Leakage ................................. 21

\section{TABLES}

Table 1. Constituents of Concern ................................. 15

Table 2. Leak Detection/Monitoring Technology Summary Sheet $\ldots \ldots \ldots \ldots \ldots \ldots . \ldots . \ldots . \ldots$ 


\section{ACRONYMS}

$\begin{array}{ll}\text { ALARA } & \text { As Low As Reasonably Achievable } \\ \text { CAT } & \text { Current Available Technology } \\ \text { CCTV } & \text { Closed Circuit Television } \\ \text { DST } & \text { Double Shell Tank } \\ \text { ERT } & \text { Electrical Resistivity Tomography } \\ \text { HTG } & \text { Hydrostatic Tank Gauging } \\ \text { ISSTRS } & \text { Initial Single Shell Tank Retrieval System } \\ \text { LDMM } & \text { Leak Detection, Monitoring, and Mitigation } \\ \text { LDT } & \text { Leak Detection Technologies } \\ \text { LOW } & \text { Liquid Observation Well } \\ \text { MAL } & \text { Minimal Achievable Leakage } \\ \text { MEI } & \text { Maximally Exposed Individual } \\ \text { NPSH } & \text { Net Positive Suction Head } \\ \text { SCC } & \text { Stress Corrosion Cracking } \\ \text { SST } & \text { Single-Shell Tank } \\ \text { TDR } & \text { Time Domain Reflectometry } \\ \text { TLV } & \text { Threshold Leakage Value } \\ \text { TWRS } & \text { Tank Waste Remediation System } \\ \text { WHC } & \text { Westinghouse Hanford Company }\end{array}$




\section{DEFINITIONS}

Interstitial Liquid - Liquid contained within a matrix of solids (i.e., saltcake and sludge in the SSTs). This consists of both bound (held in place by capillary forces) and drainable liquids.

Drainable Interstitial Liquid - Interstitial liquid that is not held in place by capillary forces, and can therefore migrate or move by gravity.

Interstitial Liquid Level - The level at which drainable interstitial liquid begins. This is in contrast to areas with bound interstitial liquid which is perhaps best described as moist sludge or saltcake.

Leak - For this report, a leak is defined as a loss of single-shell tank waste material to the surrounding soil by leakage through the tank liner and concrete or leakage from a transfer line while retrieval is occurring.

Leak Detection - A method for determining the occurrence of a leak as close to the time it happens and with as small a leak volume as possible.

Leak Monitoring - Any number of methods or combinations thereof for determining the size, rate, location, plume size, and any other desirable information about a detected leak. The time frame in which this occurs after a leak is detected is not specified.

Supernate - The free liquid above the solids in waste storage tanks. 


\subsection{INTRODUCTION}

This report is being prepared to provide an overview of the various aspects of the Initial SingleShell Tank Retrieval System (ISSTRS) program and specific operational methods for reducing the likelihood and consequences of potential leaks occurring during sluicing of single-shell tanks (SSTs). The generic concepts for selecting appropriate tanks for retrieval, utilization of the best sequence of sluicing operations, the best available leak detection, and responses to detected leaks provide a foundation for preparation of detailed procedures planned to govern the initiation of SST retrieval.

Throughout this document, the term "leak detection" is utilized to describe any method used for determining whether a tank has leaked or is leaking. The term "leak determination" is probably more appropriate for most of these methods as a tank may no longer be leaking by the time it is determined a leak has occurred. Nevertheless, the term "leak detection" is used throughout this document in order to be consistent with earlier work. The reader should keep this in mind particularly when the mass balance method for "leak detection" is presented as this is an example of an operational method for leak determination as opposed to a "detection" tool in the strictest sense.

\subsection{Background}

\subsubsection{TPA Milestones}

Tri-Party Agreement (TPA) Milestone M-45-08 addresses the mitigation of tank leakage during waste retrieval operations. Milestone M-45-08-T02 requires the establishment of criteria to determine allowable leakage volumes and acceptable Leak Detection, Monitoring, and Mitigation (LDMM) measures to permit retrieval operations. This report addresses the leak detection, leak monitoring, and leak mitigation areas. Because the candidate ISSTRS retrieval technology (sluicing) introduces significant liquids to SSTs, one of the goals of the ongoing LDMM activity is to support the TPA milestone by combining all aspects of retrieval to assure Minimal Achievable Leakage (MAL). Another goal is to identify Current Available Technology (CAT) for leak detection to support detection of leaks at the earliest time, again to ensure MAL occurs during retrieval operations. Leak Detection Technologies (LDTs) identified within this study have been evaluated along with retrieval operational considerations so that development of closure and other related risk reduction activities related to SSTs can be effectively developed. Leak monitoring was investigated only in support of leak detection. Leak monitoring plays no role in detecting a tank leak but rather could be used as a tool after the fact to assess impacts of the leak. 


\subsubsection{Waste Storage/Retrieval}

There are 149 SSTs and 28 double-shell tanks (DSTs) at the Hanford Site. These tanks were designed to store high-level radioactive wastes generated during the defense production efforts. The first SSTs became operational during the 1940s and many still contain high-level wastes. The DSTs were initially placed into service in the $1970 \mathrm{~s}$. The existing DSTs remain in service and are expected to support the cleanup mission through 2028.

The SSTs have been inactive since November 1980. Inactive, in this context, means that the tanks no longer receive waste and have been isolated from any input waste streams. Each tank farm is isolated from active facilities as a unit, generally at the nearest process pipeline diversion box.

Currently, 67 SSTs are classified as assumed leakers. An estimated 2,271 to $3,407 \mathrm{~m}^{3}$ (600,000 to 900,000 gallons) (Hanlon 1995) of waste has leaked from these tanks over the past $\mathbf{4 0}$ years. Leaks have resulted primarily from general corrosion, stress corrosion cracking, and mechanical damage in various locations in the tanks. In some cases, leak pathways have subsequently been plugged with waste salts.

In 1975, a Congressional milestone mandated that all Hanford SSTs be removed from active service by 1981. This milestone was achieved in November 1980 (WHC 1993). An interim stabilization program to reduce the liquid waste volumes in all free SSTs is ongoing. Free liquid is pumped out to the extent possible to minimize the potential environmental impact in the event of a tank leak. The status of each of the SSTs and estimates of the leaked volumes are provided in periodic status reports (e.g., Hanlon 1995). Because of the need to retrieve the waste remaining in SSTs for processing and disposal, a multi-phase effort is underway to remove the remaining SST waste and store it within DSTs until final disposal. The phases are:

- $\quad$ Salt Well Pumping - The pumping of free liquid from SSTs to DSTs,

- Sluicing Demonstration - The removal of high-heat sludge from Tank 241-C-106 utilizing past practice sluicing and transfer of this waste to Tank 241-AY-102,

- Initial Single-Shell Tank Retrieval System (ISSTRS) - The planned retrieval of the saltcake and sludge from selected SSTs, and

- $\quad$ Retrieval - Removal of remaining waste in the SSTs by 2018 to support the Hanford cleanup.

The salt well pumping is currently underway and is scheduled to be completed by 1999 . 
Waste in Tank C-106 is planned for retrieval in 1997 to provide a demonstration of retrieval technology (Cruse, et al., 1995).

With the exception of Tank C-106, retrieval of waste from all SSTs currently is planned to be completed in a 15-year campaign beginning in 2003 and ending in 2018.

\subsection{Description of the SSTs}

The SSTs are cylindrical dome-topped tanks constructed of reinforced concrete with an inner steel liner. They are classified as 100 series $(530,000$ gal., 758,000 gal, or $1 \mathrm{Mgal}$.) or 200 series tanks (55,000 gal.). Figure 1 illustrates these configurations. The 100 series SSTs are the focus of this report. Tanks in this series are 75 feet in diameter, have a minimum of 5 feet of soil cover atop the dome, and a below-grade invert elevation of 37 to 50 feet.

The concrete shell supports the surface loads and the internal hydrostatic and hydrodynamic loads (WHC 1993). The welded steel liner, which extends almost up to the joint between the wall and dome, is structurally independent of the concrete tank. The purpose of the steel shell is to provide containment of the stored liquid waste (WHC 1993). An asphalt composition material is placed between the steel liner and the concrete tank to provide an additional moisture barrier.

In addition to the inter-tank pipelines, other structures/components associated with the tanks, and tank farms may include (Figure 2):

- $\quad$ active ventilation and exhaust systems (including radiation monitoring systems),

- passive ventilation systems,

- tank temperature instrumentation,

- interior leak detection and monitoring [tank liquid-level instrumentation, liquid observation wells (LOWs)],

- $\quad$ exterior leak monitoring (vertical dry wells, lateral wells),

- $\quad$ support systems [area radiation monitors, steam supply (241-SX), AC power, raw water supply, instrument air supply],

- $\quad$ salt well pump, and

- $\quad$ miscellaneous pits (pump pits, sluice pits, valve pits, flush pits, service pits), diversion boxes, vaults, catch tanks.

SSTs typically store waste in a manner depicted in Figure 3.

The typical interstitial liquid currently within the SSTs is variable and dependent upon individual tank history which is not always well known. Boomer, et al., (1993) provided a general 

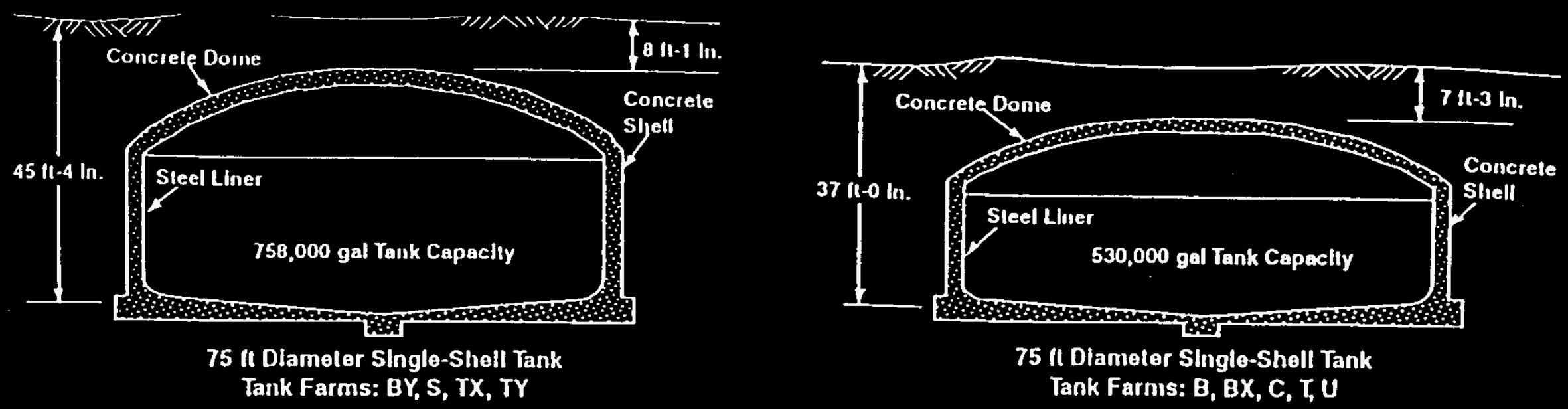

Tank Farms: BY, S, TX, TY

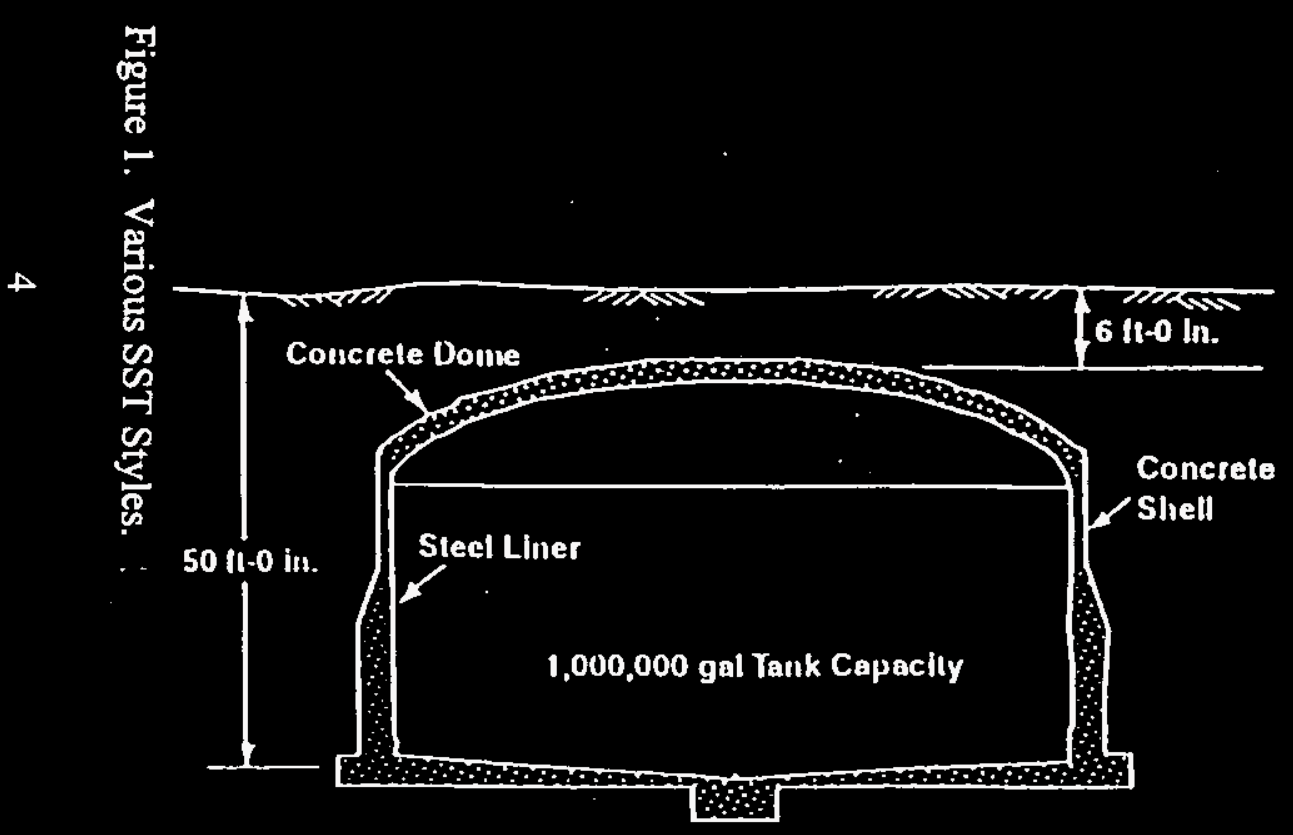

75 II Dianneter Slngle-Slıell Tank

Tank Furuis: $A^{\circ}, A X^{\circ}, S X$

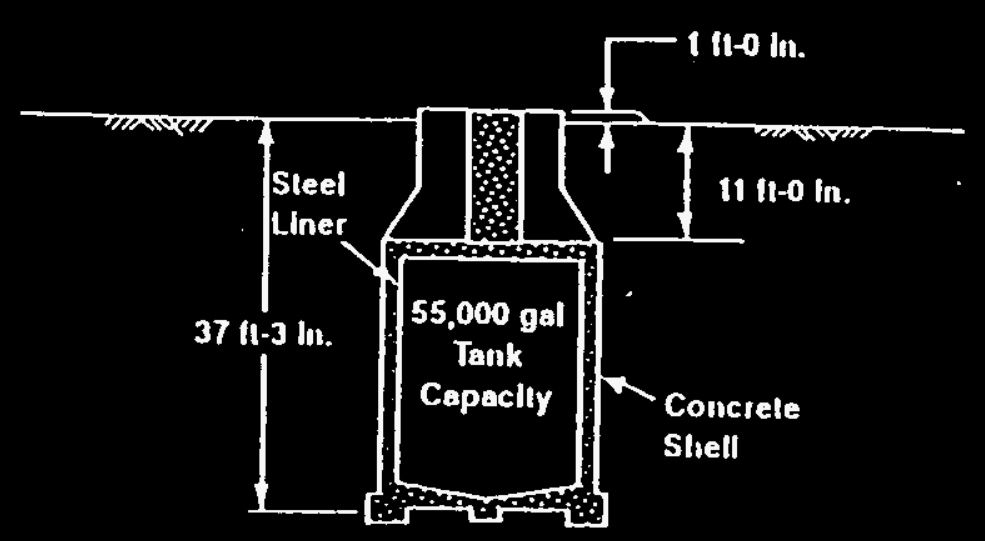

- A and AX have llat bollums

20 ft Dlameler Single-Shiell Tank Tank Farms: B, C, T, U 
WHC-SD-WM-ES-377, Rev. 0

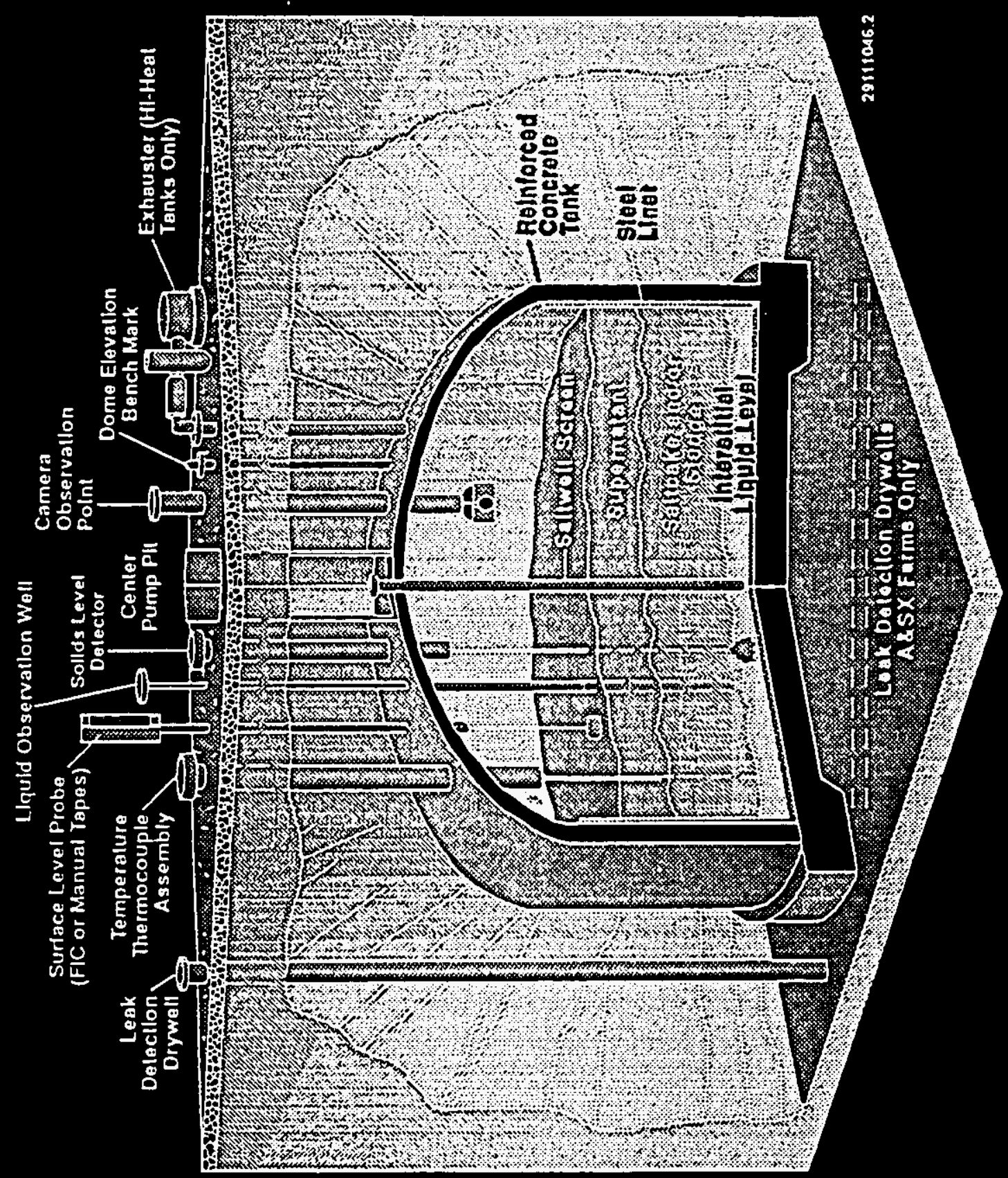

Figure 2. Typical SST Configuration 
WHC-SD-WM-ES-377, Rev. 0

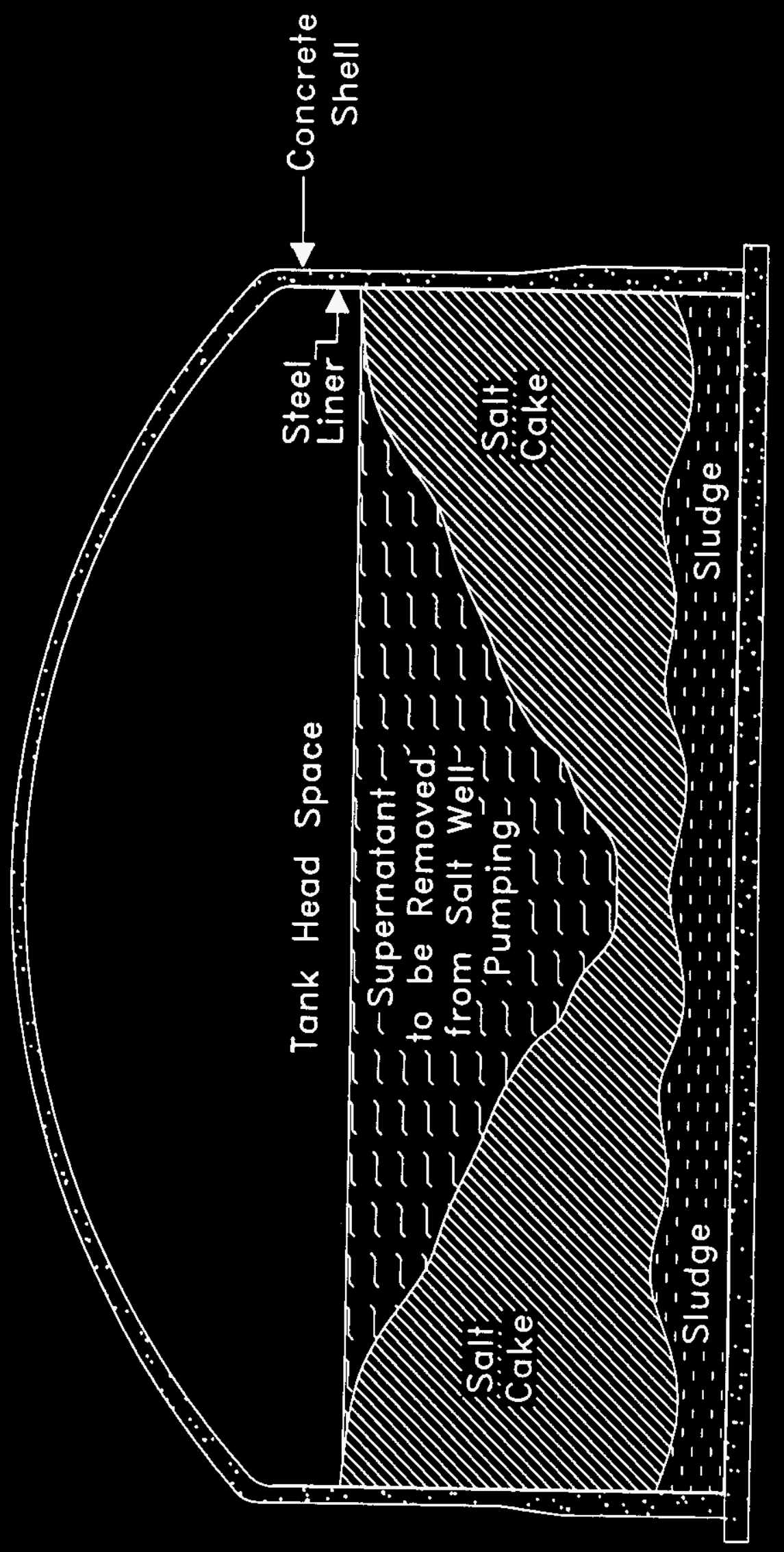

Figure 3. SST Waste Storage. 
description that indicates that the liquid wastes consist primarily of (in descending relative weight concentrations) water, $\mathrm{Na}^{+}, \mathrm{NO}_{3}^{-}, \mathrm{NO}_{2}^{-}, \mathrm{PO}_{4}^{-3}, \mathrm{OH}, \mathrm{Al}^{+3}$, and organic carbon. The radionuclide components of SST wastes consist primarily of fission radionuclides such as ${ }^{90} \mathrm{Sr}$ and ${ }^{137} \mathrm{Cs}$, and actinide elements such as U, Pu, and Am (Cruse and Treat 1994).

\section{$1.3 \quad$ SST Leakage}

A discussion of past SST leaks is included here to provide a reference frame for the reader as to the size and rate of leaks that occurred during normal operations.

A total of 67 SSTs are assumed to have leaked to date. The total waste volume leaked is estimated to approach $900 \mathrm{kgal}$ (Hanlon 1995). Utilizing data from various leaking tanks, it is believed that most tank leaks occur at relatively low rates $(<0.03 \mathrm{gal} . / \mathrm{min}$.) (Johnson 1995).

One of two cases where much greater leak rates have occurred was the Tank 241-T-106 leak which is suspected to have been caused by the tank undergoing significant structural failure. This is probably the best documented leak and the following description of this event [taken from Freeman-Pollard, et al., (1994)] follows.

- $\quad$ Between January 1973 and April 4, 1973, the liquid level in Tank 241-T-106 was essentially stable at 24 inches. Starting on April 4, 1973, liquid waste was added to the tank. The measured waste level on April 23 was 153.3 inches. The waste level on April 24 , at the end of the filling operation, was 183.7 inches. This leak apparently began on April 20, 1973 (based on material balances) and continued until June 10, 1973, when the tank was pumped to remove all of the liquid waste. The total leak volume was approximately 115,000 gallons.

The fact that the tank was stable before the waste was added suggests that the leak probably occurred through the wall, somewhere between the 24 (the level before filling) and 153.3 inch level (the measured level on April 23). Examination of a plan and cross-sectional view of ${ }^{106} \mathrm{Ru}$ distribution from Brown, et al. (1979) shows contamination beginning at approximately the 133 inch level outside the southeastern side of the tank. The shape of the plume in 1979 was ellipsoidal, approximately 177 feet by 155 feet by 66 feet deep. During the 1973 drilling investigation, a previously unknown leak was also found on the east side of Tank 241-T-103, immediately north of Tank 241-T-106 (ARCO 1973). The cause of the leak from 241-T-103 was suspected to be a failed grout seal in a spare fill line. The volume of soil originally contaminated by leaks from Tanks 241-T-106 and 241-T-103 was 25,000 $\mathrm{m}^{3}$, respectively (ARCO 1973). 
In all tanks, regardless of whether they have leaked or not, the combination of conditions that can lead to leaks is still present, although to a reduced degree. Leak probability is a function of SST age, its content, and the location of the drainable liquid within the available space. Because almost all of the liquid has been removed from the SSTs, the potential for leakage has been greatly reduced. Waste retrieval processes, however, will increase this potential since the chosen method for initial retrieval in a sound (non-leaking) tank involves liquid addition (sluicing).

If a SST leak occurs, there are four key parameters that will affect the impact to the environment: 1) presence of lateral inhomogeneities within the soil layers [since lateral transport dominates typical and median size spills (660 and 5,200 gal., respectively)], 2) adsorptive properties of the Hanford soil formation that can retard transport of some species, such as ${ }^{137} \mathrm{Cs}$ and ${ }^{90} \mathrm{Sr}, 3$ ) waste constituents, and 4) quantity of wastes leaked. A fifth parameter that has been proposed for further study is the existing moisture content in the vadose zone in the vicinity of the tanks. Sources of existing moisture are from prior leaks and/or enhanced runoff occasioned by the presence of the tanks.

The first step in the initial retrieval process will be to try to avoid a leak by correct tank selection and minimization of liquid addition. The other aspect of the retrieval effort that can limit consequences of a tank leaking is the minimization of leak volume.

Of greatest importance to the retrieval effort to minimize leakage is the historically low leak rate. This is because of the limited amount of time that drainable liquids will be in the tank during retrieval. Reviews of historical leak rates in 1981 (Johnson 1995) revealed that excluding Tanks 106-T and 110-SX which experienced significant leakage rates due to suspected structural problems, the maximum leak rate was estimated to be $<0.03 \mathrm{gal} / \mathrm{min}$ at a 95 percent confidence interval. This equates to $43.2 \mathrm{gal} / \mathrm{day}$ or $1296 \mathrm{gal} / \mathrm{month}$. Clearly, at these rates, it takes a considerable time period without an operational response to leak large amounts of liquid from an SST during retrieval.

From these discussions, it can be determined that to best minimize SST leakage, the goals of the sluicing effort must be to: 1) minimize the amount of liquid in contact with surfaces with the greatest leak potential, 2) have the ability to detect a leak with a very low leak rate over a relatively short time, and 3) take appropriate operational actions to minimize the amount of liquid leaked. As this report will show, Items 1 and 3 can be more readily performed than can Item 2. 


\subsection{OBJECTIVES}

There are four primary objectives to be accomplished by this document in support of the ISSTRS. These objectives are:

- Development of a detailed SST retrieval methodology to produce MAL,

- Evaluation of currently available technology to recommend the preferred leak detection system in support of MAL,

- Development of categories of leakage as a function of the consequence. An initial baseline has been established and is known as the Threshold Leakage Value (TLV), and

- Development of operational responses to a suspected or confirmed leak during retrieval for each category of leak.

Details of each of these objectives are presented in the following sections:

- Section 3.2 Recommended SST Retrieval Planning,

- Section 4.2 Categories of Leakage,

- Section 4.3 Leak Detection Technology,

- $\quad$ Section 5.3 Operational Response to SST Leaks, and

- $\quad$ Appendix C ISSTRS Operational Leak Response.

\subsection{ISSTRS RETRIEVAL METHODOLOGY}

\subsection{Existing SST Contents}

The SSTs on the Hanford Site have been used to store radioactive hazardous waste produced for defense purposes since the 1940s. The SSTs were removed from active service in 1980 and the remaining free liquid in the tanks has been, or will be, pumped to newer DSTs. What remains is a combination of saltcake (primarily sodium nitrate and sodium nitrite), sludge (sodium aluminate, metal oxides, etc.), supernate liquid, and interstitial liquid. An SST that has been pumped is considered interim stabilized if it has less than 50,000 gallons of drainable interstitial liquid and less than 5,000 gallons of supernate. Current schedules (TPA-M-41-00 and TPA-M45-00) show all the SSTs being interim stabilized by 1999 and all SST wastes retrieved for final disposition by 2018.

In order to remove the remaining free liquid and stabilize the tank, what is known as a "salt well system" is inserted into the tank. The salt well system is a ten-inch diameter stainless steel salt well screen welded to a schedule 40 carbon steel pipe that serves as the casing. The casing and 
screen are lowered into the tank through a 12 -inch riser in the pump pit of the tank. The screen portion is approximately 10 -feet long and will extend to near the bottom of the tank when installed. A jet pump is then lowered into the salt well screen and interstitial liquid is pumped out until the interim stabilization criteria is met and the jet pump is no longer capable of pumping more than $0.05 \mathrm{gpm}$ (Hanlon 1995). When pumping is completed, the jet pump and the salt well screen are removed. The saltcake, sludge, and interstitial liquid that remains often slopes towards the center of the tank where the salt well system was located (Figure 3). In this condition, only the drainable interstitial liquid is considered capable of leaking from the tanks. In several interim isolated tanks there is considered to be no drainable interstitial liquid, while in some there is greater than 20,000 gallons of drainable interstitial liquid. In either case, the result of salt well jet pumping is to reduce the hydrostatic head of the remaining liquid to minimize what driving force for tank leakage there is.

\subsection{Recommended SST Retrieval Planning}

Currently, several methods of SST retrieval are under investigation for future retrieval campaigns in support of the Tank Waste Remediation System (TWRS) (Boomer 1993). Proposed methods include mechanical (e.g., robotic arms and end effectors), pneumatic (e.g., vacuum system), and hydraulic (e.g., sluicing). The selected method for the ISSTRS is sluicing (Lewis 1995). In sluicing, an articulated arm with a nozzle is utilized to introduce water (or other liquids such as sodium hydroxide) as either a cutting tool or as a spray which erodes and dissolves solid waste and suspends the solid particles in a slurry that can then be removed from the tank by pumping. Three types of sluicing exist as available technology.

- Past practice sluicing uses existing risers for sluicer access to the tank, articulated arm sluicers, and existing pump pits for slurry pumps. High-pressure water is used and a minimal amount of control is employed over where the water spray contacts, in comparison to limited or confined sluicing. Uncontrolled contact of the direct spray with the tank wall is likely.

- Limited sluicing can also use existing risers and pump pits with an articulated arm sluicer. However, the nozzle is maintained closer to the waste and tighter control over the flow volume and direction is exercised. Closed circuit television (CCTV) can be used (but is not required) to monitor progress and indicate where the sluicing stream should be directed. During actual use of the sluicer, the CCTV will have a limited view of the work area while water is flowing due to the spray fog that will be developed. Uncontrolled contact of secondary water spray (water rebounding from the tank waste) with the tank wall is still likely. 
- Confined sluicing is a process using an articulated arm with a small (approximately three foot) dome at the end. The dome contains several water and air nozzles that are used for localized sluicing under the dome. Uncontrolled contact of the water spray with the tank wall would require operator error or intent.

A study conducted by Gibbons, et al. (1993), and cited in Lewis (1995), concluded that past practice sluicing is the first choice retrieval technology where tank leakage is not a concern. This has been interpreted to mean that only tanks judged to be "sound" non-leakers are to be retrieved by sluicing.

Most leaks from SSTs that have occurred are believed to have originated high in the tank wall at past liquid/vapor interfaces (Boomer, et al., 1993) where the presence of oxygen assists general and pitting corrosion. Over time, the integrity of the steel liners in the SSTs are under attack from a potential combination of general pitting and stress corrosion cracking (SCC).

Westinghouse Hanford Company (WHC) has proposed that some of the leaking SSTs sustained through-wall SCC first, then subsequently sustained equally damaging pitting and general corrosion attack. SCC preferentially attacks welds in the SST steel liners because they were not stress relieved following fabrication (Lewis, et al., 1995). Because of this, high stress regions such as the tank knuckle may also be more likely places for tank leakage to occur.

Because of past leakage in the SST liners, and the potential for future leakage (particularly during retrieval), a retrieval sequence has been proposed for use with limited sluicing that will result in a minimal amount of leakage even if a leak path exists. By only placing minimal amounts of liquid in the tank and by sluicing in a controlled manner, the likelihood of a leak is minimized. Should a leak occur, the consequences of the leak are significantly mitigated due to the minimal liquid (and thus, minimal hydrostatic driving force) and by the limited amount of time the liquid is in contact with the leak path. It must be stressed here that the use of this limited sluicing technique is probably the single most important factor in reducing the likelihood and consequences of a leak. It is likely that up to 85 percent of the existing waste could be retrieved with very minimal additional liquids coming in contact with the tank walls, and minimal amounts reaching the tank bottom. Use of this method is the primary reason that the low historical leak rate of $<0.03 \mathrm{gal} / \mathrm{min}$ is used as a baseline in this report. Past leaks occurred with large volumes of liquids in the tanks. The retrieval sequence is shown pictorially in Figure 4 and described as follows:

- $\quad$ First, liquid is added to the tank to establish a consistent waste level from which to calculate the waste volumes (Figure 4a). This creates a situation where a relatively accurate waste volume baseline is established and where relatively small changes in 
volume can be detected. However, it is recognized that any addition of liquid of this nature can increase the potential for leakage. Other methods, such as photogrammetry, may be utilized to determine with improved accuracy the initial volume of an uneven, solid surface. Photogrammetry has not been utilized in a tank to date but in theory should operate very well and is recommended for further evaluation.

- Next, waste is removed near the center of the tank where the retrieval pump is located and a sump to provide suction head for the pump can be established without the liquid coming in contact with the tank walls (Figure $4 \mathrm{~b}$ ). Waste removal continues by limited sluicing (i.e., close control of the sluicing nozzle location) and maintenance of a restricted zone within one to two feet of the tank wall, bottom, and knuckle region. The actual thickness of this zone will be a function of the stability of the waste. A minimal liquid level should be maintained (i.e., only enough to meet NPSH required) to further minimize the potential for a leak and the amount that could leak. In the area where sluicing spray is actually directed, the liquid level could be less than one foot and still allow sluicing to be effective.

- Once all waste outside of the restricted zone is removed, the next phase is to remove all waste along the wall above the knuckle region. It will be possible at this point to maintain the liquid level well below the working point so that only a minimal amount of leakage could occur if a liner breech takes place. Again, limited sluicing is used and a minimal liquid level is maintained (Figure $4 \mathrm{c}$ ). Note that Figures $4 \mathrm{c}$ and $4 \mathrm{~d}$ are representative of a primarily saltcake tank. Where the tank contents are primarily sludge, the waste may be more likely to slough off the walls as sluicing proceeds.

- Once all waste from the wall above the knuckle region is removed, the next phase is to remove all waste along the bottom of the tank. This is a region where the probability of a leak is somewhat lower than at the knuckle because the knuckle is a high stress region. Waste should be removed from the center of the tank outward while utilizing limited sluicing and maintaining a minimal liquid level (Figure 4d).

- Once all waste from the tank bottom has been removed, the last phase is to remove all remaining waste from the knuckle region. As always, limited sluicing while maintaining a minimal liquid level should be used (Figure 4d).

During each of these steps, leakage detection through mass balance analysis is being performed. In the event of detection of a leak, specific actions will be implemented. The actions are dependent on the location and nature of the leak, as well as the stage of tank retrieval when a leak 


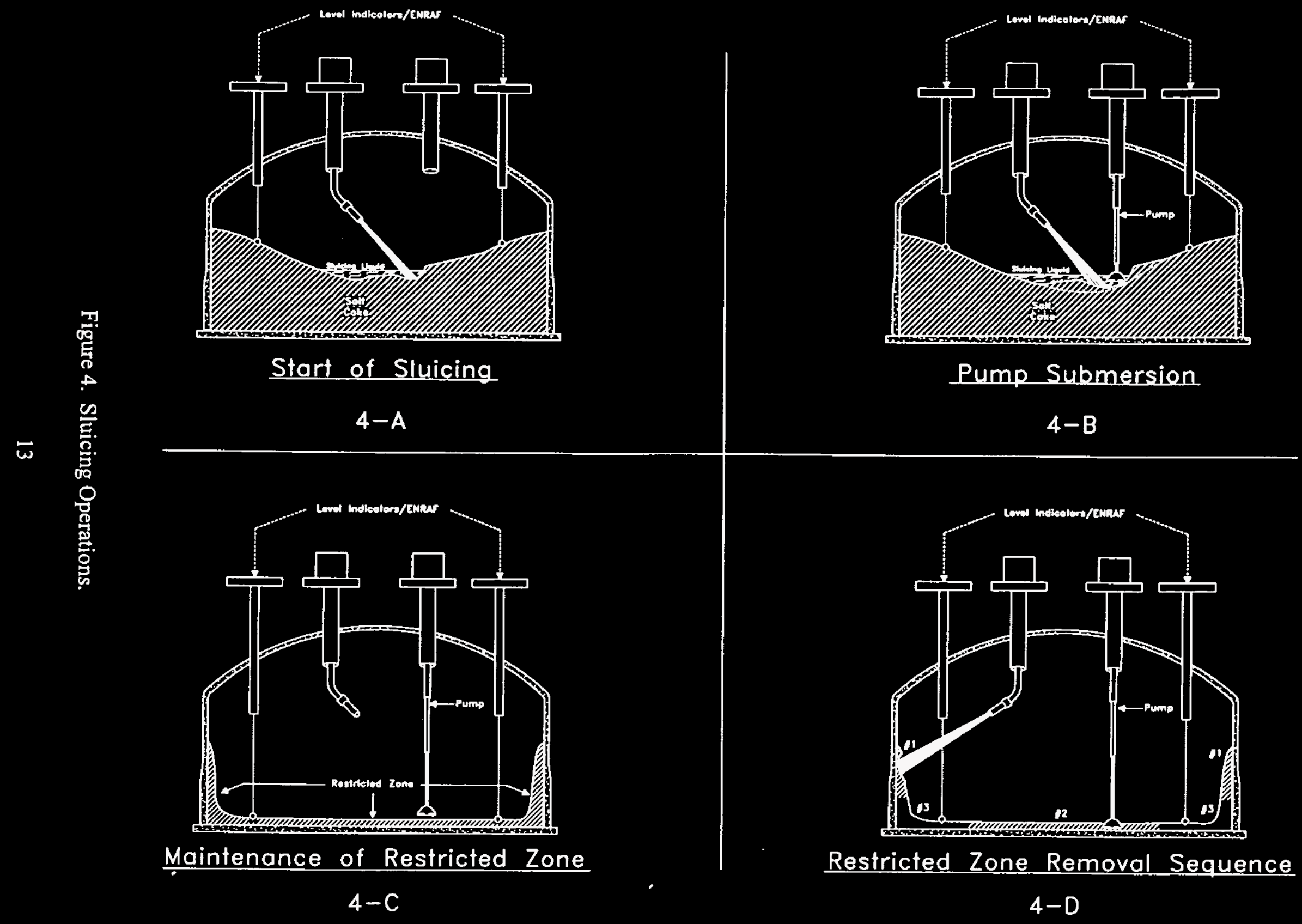


is detected. The remainder of this report deals with detection of leaks and operator actions necessary to respond to the detection.

\subsection{CURRENT AVAILABLE LEAK DETECTION TECHNOLOGY}

\subsection{Allowable Leak Values}

The objective for establishing allowable leak values is to provide a methodology for assessing the impact upon the health and safety of the general public due to the volume of leakage from one or a combination of underground storage tanks at the Hanford Tank Farms. The other reason this is done is that no leak detector can determine an infinitesimally small leak, therefore, it is necessary to have an objective criteria to evaluate leak detection technologies.

Preliminary allowable leakage values have been determined and will be used in this report as a baseline. However, it needs to be stressed that additional study and modeling is necessary to refine these values. These preliminary values have been called Threshold Leakage Values (TLVs).

The methodology for the development of TLVs is addressed in Appendix C of Cruse (1995). The initial values reached regarding risk are acknowledged to be preliminary and are considered a first approximation to be used for ongoing evaluation of SST leaks. However, the method used to arrive at the values is sound in its approach to assessing the impact of SST leaks to a maximally exposed individual (MEI). The authors of this document believe this is a highly conservative approach in applying the exposure of the MEI to the general public. These values for leakage can be expected to be more finely tuned as more tank characterization data becomes available and more refined exposure estimate models are developed. In their current state, they can be used for assessing relative risk between the tanks.

The methodology of Cruse (1995) provides preliminary SST TLVs based upon carcinogenic and toxicological risk. Without going into too much unnecessary detail, the general methodology used is presented here. First, constituents of concern (COCs) were established from a risk standpoint. The COCs developed are presented in Table 1 and were primarily drawn from data in Droppo (1991). Droppo determined that constituents that resulted in a potential carcinogenic risk (R) greater than 1.0 E-06 or a non-carcinogen hazard index $(\mathrm{HI})$ greater than 1.0, based on the transport model used, were to be considered COCs.

The specific risk index values $(\mathrm{R} / \mathrm{g}$ or $\mathrm{HI} / \mathrm{g})$, also shown in Table 1 , were then derived based on the model and approach documented in Treat (1994). The values indicate the potential peak risk 
WHC-SD-WM-ES-377, Rev. 0

\begin{tabular}{|c|c|c|c|c|c|}
\hline & Specific Activity & Specific Risk Index & $\begin{array}{l}\text { Adsorption } \\
\text { Coefificient }\end{array}$ & $\begin{array}{l}\text { Max. Assumed } \\
\text { Solubility }\end{array}$ & Basis \\
\hline Constituent & $\mathrm{Bq} / \mathrm{g}$ & R/g or HI/g & (Kd) & $g / L$ & Note 5 \\
\hline \multicolumn{6}{|l|}{ Radionuclides } \\
\hline Americium, Am241 & $1.27 E+11$ & $3.92 E-09$ & 8.2 & $2.91 E-04$ & $\mathrm{~d} / \mathrm{AX}-102$ \\
\hline Americium, Am241m & $2.99 E+16$ & $9.62 \mathrm{E}-04$ & 8.2 & Note 1 & \\
\hline Carbon, C14 & $1.65 E+11$ & 1.36E-06 & 0.0 & $6.73 \mathrm{E}-07$ & Sw \\
\hline Curium, Cm242 & $1.22 E+14$ & $6.99 E-05$ & 8.2 & Note 1 & \\
\hline lodine, 1129 & $6.44 \mathrm{E}+06$ & $2.52 \mathrm{E}-13$ & 0.0 & $1.72 E-03$ & sw \\
\hline Niobium, Nb93m & $1.05 \mathrm{E}+13$ & 5.18E-04 & 1.2 & Note 1 & \\
\hline Neptunium, Np237 & $2.61 \mathrm{E}+07$ & $8.77 E-13$ & 3.0 & 1.98E-01 & sw \\
\hline Plutonium, Pu238 & $6.33 E+11$ & $2.14 E-08$ & 10.0 & $5.85 E-06$ & sw \\
\hline Plutonium, Pu239 & $2,30 E+09$ & $7.41 \mathrm{E}-11$ & 10.0 & $6.09 \mathrm{E}-02$ & $\operatorname{sn} / \mathrm{U}-109$ \\
\hline Plutonium, Pu240 & $8.44 E+09$ & Note 2 & 10.0 & Note 2 & \\
\hline Plutonium, Pu241 & $3.74 E+12$ & $7.69 E-06$ & 10.0 & $9.90 E-07$ & sw \\
\hline Technetium, Tc99 & $6.29 E+08$ & 3.58E-09 & 0.0 & $2.70 \mathrm{E}-02$ & sn/BY-102 \\
\hline Uranium, U233 & $3.57 E+08$ & Note 3 & 0.0 & & \\
\hline Uranium, U234 & $2.32 E+08$ & Note 3 & 0.0 & & \\
\hline Uranium, U235 & $7.99 E+04$ & Note 3 & 0.0 & & \\
\hline Uranium, U238 & $1.24 E+04$ & $3.29 E-15$ & 0.0 & $3.84 E+02$ & sn/BX-112 \\
\hline
\end{tabular}

Chemicals/Elements

\begin{tabular}{|c|c|c|c|c|c|}
\hline Arsenic, As & $\pi / a$ & $2.765-15$ & 0.6 & 3.45E-01 & $d r$ \\
\hline Beryllium, Be & $n / a$ & Note 4 & 0.0 & & \\
\hline Cyanide, CN & $n / a$ & $5.32 E-08$ & 0.0 & $9.13 E-02$ & $\mathrm{sn} / \mathrm{C}-102$ \\
\hline Chromium, $\mathrm{Cr}$ & $n / a$ & 1.18E-16 & 1.0 & $1.00 E+01$ & sw \\
\hline Copper, Cu & $n / a$ & 1.34E-07 & 4.2 & $3.45 E+00$ & $d r$ \\
\hline EDTA & $n / a$ & 5.02E-07 & 0.0 & $2.81 E-02$ & $d r$ \\
\hline Flouride, $\bar{F}$ & $n / a$ & $7.525-10$ & 0.0 & $6.02 E+00$ & $\mathrm{sn} / \mathrm{T}-110$ \\
\hline Mercury, $\overline{\mathrm{Hg}}$ & $\overline{n / a}$ & $1.30 \mathrm{E}-06$ & 0.0 & $3.20 \mathrm{E}-01$ & $\mathrm{dr}$ \\
\hline Sodium, Na & $n / a$ & 2.75E-13 & 0.0 & $3.56 E+02$ & dl/SX-104 \\
\hline Nitrite, NO2 & $n / a$ & $9.09 E-10$ & 0.0 & $1.41 E+02$ & d//C-109 \\
\hline Nitrate, NO3 & $n / a$ & $7.69 E-10$ & 0.0 & $4.09 E+02$ & dl/SX-104 \\
\hline Antimony, Sb & $n / a$ & $9.26 E-08$ & 0.0 & $8.46 E+00$ & $d r$ \\
\hline Sulfate, SO4 & $n / a$ & $1.81 E-12$ & 0.0 & $9.70 E+00$ & $\operatorname{sn} / \mathrm{A}-102$ \\
\hline Vanadium, V & $n / a$ & 4.29E-09 & 0.0 & $8.46 E+00$ & $d r$ \\
\hline
\end{tabular}

Notes:

1. Solubility data not available.

2. Pu239 and Pu240 were combined in the analysis as Pu239.

3. The Uranium isotopes were combined in the analysis as U238.

4. Berylium was not analyzed since no current reports indicate its presence in any tank.

5. Symbols as follows: "dl/ $x-x \times x "$ means based on drainable liquid sample from tank $x-x x x$, "sn/ $x$-xxx" means based on supernate sample from tank $x-x x x$, "sw" means based on data from Serne \& Wood (1990), "dr" means based on data from Droppo et al. (1991).

Table 1. Constituents of Concern 
to a maximally exposed individual with key assumptions of a 70-year lifetime and distribution coefficients $\left(\mathrm{K}_{\mathrm{d}}\right)$ set to zero. This would normally be a conservative approach, but in the final analysis to determine TLVs the COCs with high $\mathrm{K}_{\mathrm{d}}$ values were eliminated because they did not contribute appreciably to the total risk. The COCs that were eliminated were plutonium, americium, curium neptunium, niobium, and copper. It should be noted that the time at which such a peak occurs is approximately 19,000 years following closure of the tank farms.

Next the inventory and solubility of the COCs was established on an individual tank basis. A volume based specific risk for each tank could then be established. Finally, the TLVs were determined for carcinogens by dividing an assumed individual tank risk threshold of 1.0 E-06 by the sum of the individual volume based specific risks. The use of 1.0 E-06 assumed threshold allows for an assumption of ten leaking tanks at the threshold in order to approach ten percent of the maximum risk of $1.0 \mathrm{E}-04$ generally considered acceptable by EPA in risk assessments. The same approach is used for non-carcinogens except an assumed individual tank HI of $1.0 \mathrm{E}-02$ is used to allow for ten tanks leaking (at the threshold) in order to approach ten percent of the maximum HI (1.0) generally considered acceptable by the EPA in risk assessments. Figure 5 shows preliminary TLVs on a tank-by-tank basis. Tanks BX-108, C-202, C-203, C-204, T-107, $\mathrm{T}-111$, and TX-106 were not included on the figure since their TLVs are greater than 80,000 gallons. 


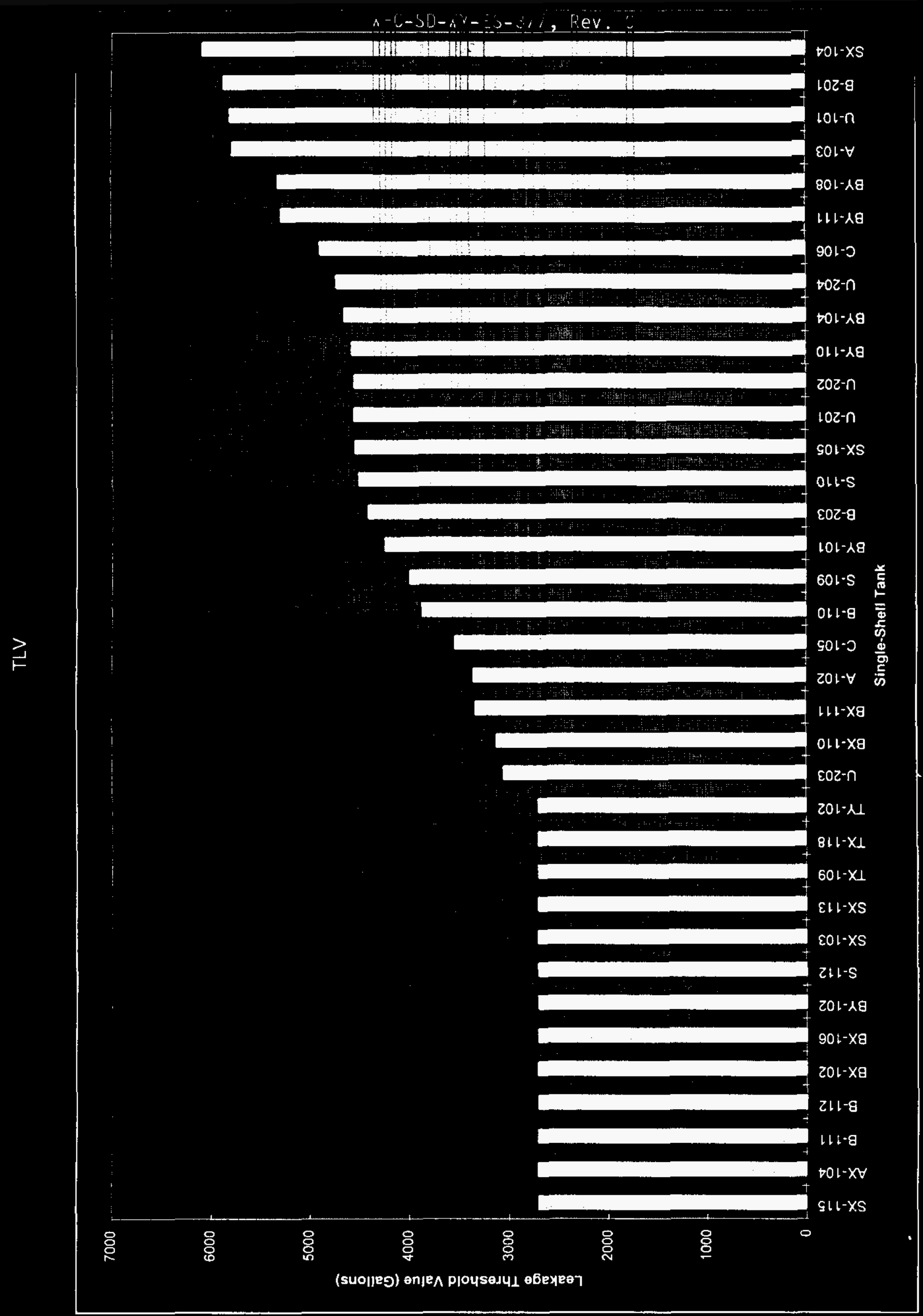

Figure 5. Preliminary SST Threshold Leakage Values 


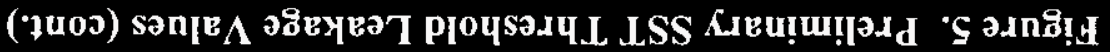

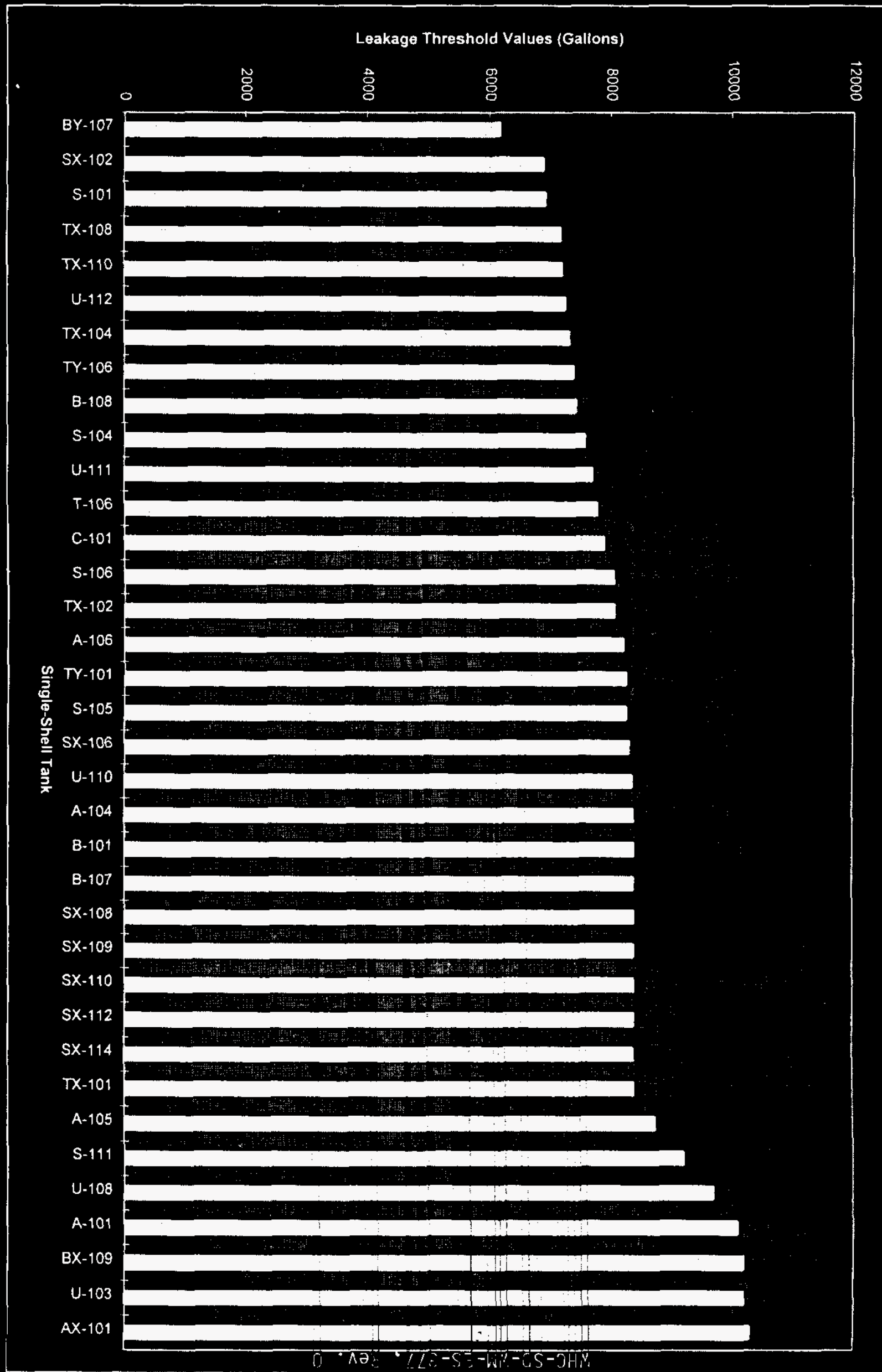




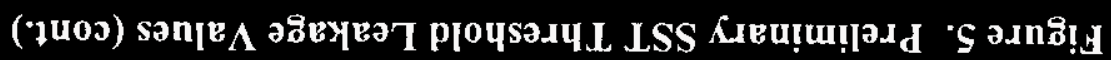

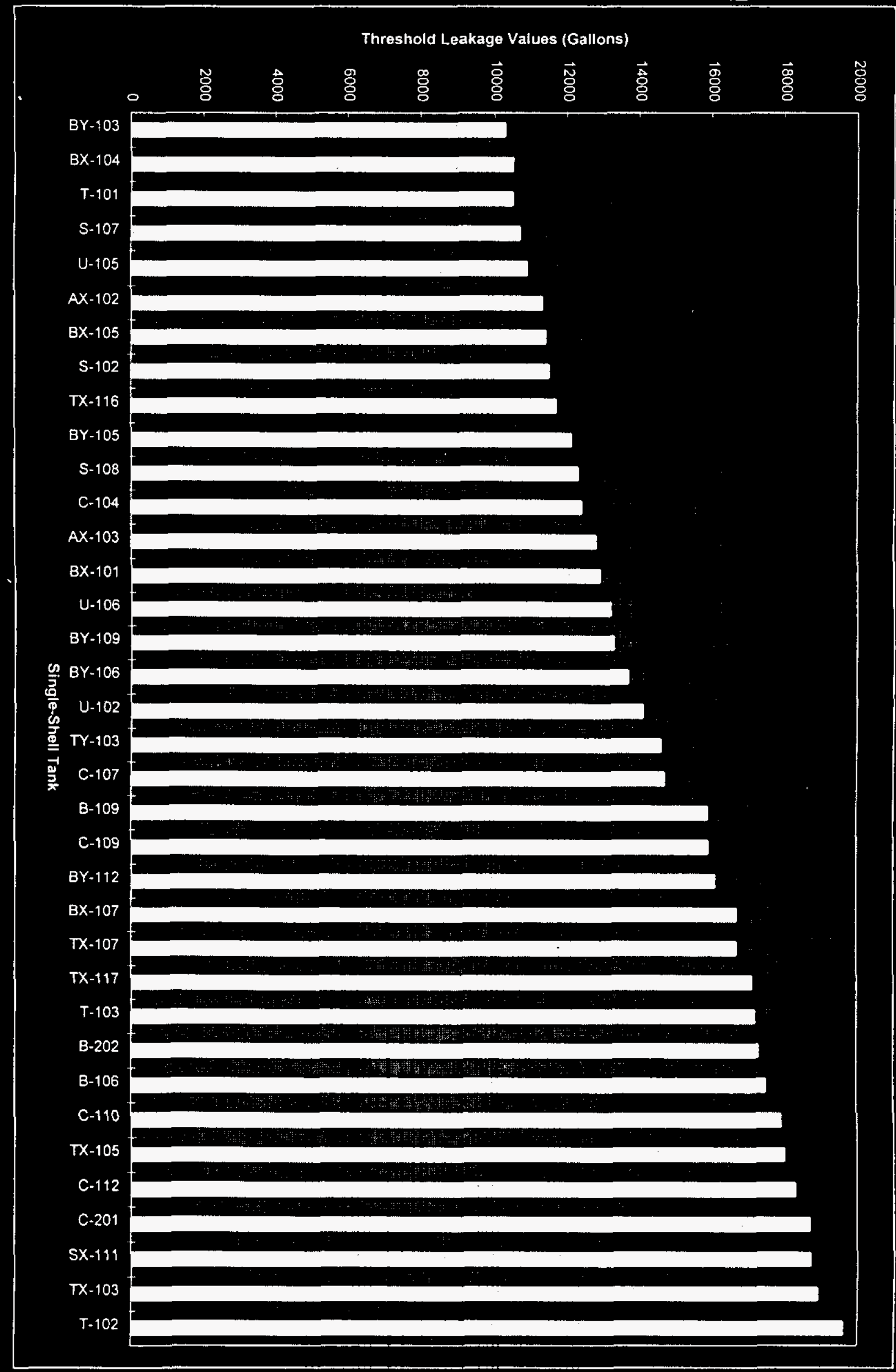




\subsection{Categories of Leakage}

In order to discuss leak detection alternatives (and ultimately Operational Responses), categories of leakage need to be identified with Boundary Limits based upon allowable leakage values and minimum detectable leakage. Figure 6 depicts three leakage categories - Minimal, Significant, and Extensive. A Minimal leak is a leak which is less than the minimum detectable leak. A significant leak is a detectable leak less than the allowable leakage value. An Extensive leak is any leak larger than the allowable leakage value. Tanks for which the allowable leakage value is less than the minimum detectable leakage should not be retrieved as part of ISSTRS and are, therefore, not addressed in this document.

The boundary limits which separate the three leakage categories are established on a tankspecific basis. They are a function of the public risk from each tank based upon the constituents of the tank contents and leak detection capability for each tank. Figure 6 depicts the established limits for each of the leakage categories.

Limit $\# 1=\quad$ minimum detectable leak

Limit $\# 2$ = allowable leakage value

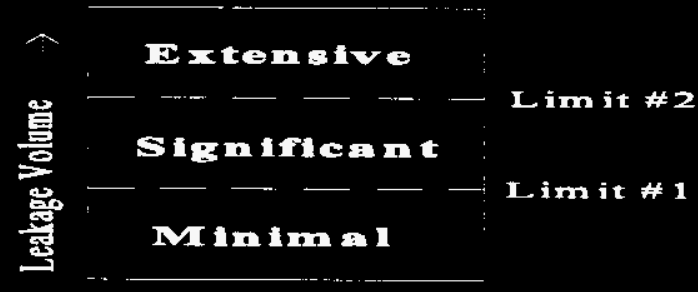

Figure 6. Categories of Leakage

The basis for the limits are that:

- Leaks smaller than the allowable leakage value have environmental consequences which pose generally acceptable risks to the public. 
- Leaks that can not be detected can not be used to establish leakage limits because they can't be measured. It should be noted here that tanks with an allowable leakage value less than the minimum detectable leakage would be candidates for using enhanced leak detection capabilities as they are developed, or an alternative retrieval method depending on the availability of alternative retrieval methods and the assessment of overall impact to risk.

\subsection{Leak Detection Technology}

In order to be considered a leak detection technology as opposed to a leak monitoring technology, several characteristics need to be investigated such as:

- $\quad$ Can the technology detect leaks independent of location and type of waste?

- Is the response timely?

- Are false positive indications minimized?

Beyond whether a technology is considered a detector or a monitor, several other important characteristics also need to be considered:

- What volume/rate of leak can be detected/monitored?

- Can leak rate be determined?

- $\quad$ Can the leak volume be determined?

- Has the technology been demonstrated on Hanford SSTs?

- Can a sufficient quantity of the soil mass surrounding the tank be "interrogated" for external technologies?

- Is the technology currently available for use?

- $\quad$ Can the technology be deployed in or around an SST?

Several technologies were identified and are discussed here with these characteristics in mind. 


\subsubsection{Mass Balances}

Mass balances have been used in the past on the Hanford Site for indication of leaks or waste transfer misroutings. To use mass balance for performing leak detection in liquid containing tanks, it is necessary to know various waste parameters such as temperature, surface level, and temperature coefficient of expansion of the liquid.

To perform a mass balance on an SST sluicing operation, however, additional knowledge is necessary due to the presence of soluble and insoluble solids in the tank and the general non-homogeneous nature of the wastes. A method for performing a material balance between stages of sluicing Tank 106-C was proposed by ARES Corporation where the liquid levels, specific gravity, and temperatures of both tanks is measured. Based on known inventories of soluble and insoluble solids prior to sluicing, it is possible to estimate the material balance within $\pm 5,570$ to $\pm 8,270$ gallons (see Appendix $B$ ). The difference in mass balance accuracies comes from the choice of density instrumentation used. A detailed description of a mass balance for the sluicing retrieval of a typical SST is given in Appendix A, while a general description applicable to all tanks follows.

Initial tank characterization data is necessary to define the mass of soluble and insoluble solids in the sluicing and receiving tanks based on the solids level, mass fraction of soluble/insoluble salts, and the porosity or liquid fraction of the solids. The mass of the liquid in both tanks must also be determined from the specific gravity of the liquid, tank waste level and porosity of the solids. Once sluicing begins, it may be appropriate to periodically pump all liquids down as low as possible in the tank being sluiced and perform an estimate of the solids content. It is currently recommended that this be done at the end of each batch sluice (approximately 16 hours). This will not impact the sluicing schedule and will allow an assessment of effectiveness, as well as refining the estimate of remaining waste. The solids are now likely to be in a more conical shape sloping towards the center, so a visual estimate is the only practical means of performing this estimate at this time. Several observers could be used to perform this estimate to develop a statistical average (Delphi technique) to improve precision. After estimating the solids content in the tank being sluiced, liquid would then be added to reinitiate sluicing. The level, temperature, and specific gravity of the liquid is then measured in the tank being sluiced to determine the mass present. In the receiving tank, to perform the mass balance it would be assumed that the soluble solids fraction that was transferred is now in solution and that a measurement of level, temperature, and specific gravity combined with the insoluble solids estimate would then be made to determine the total mass in the tank. Mass inputs (e.g., water additions) would also need to be closely gauged to maintain the mass balance. Based on the mass of inputs, temperature, specific 
gravity, mass of soluble and insoluble solids, and estimate of solids transferred the expected sum of the level of the two tanks is determined and compared to the actual sum of the level of the two tanks. If the measured level is outside of the expected (calculated) level by more than the accuracy of the method, then a leak is suspected. If a leak is suspected but cannot be confirmed, one method that should be considered is to perform a static condition mass balance. (This method is not normally recommended due to the increased potential for tank leakage, but the method is described as follows for consideration.) Liquid is added back into the SST to a height covering the solid waste. After a waiting period of two to four hours to allow for temperature equilibration and dissolving of soluble solids, the liquid level is measured with the Enraf Nonius level gauge (see Section 4.3.1.1). The level is then continuously measured and compared to this baseline to determine if a leak is occurring. With an accuracy of \pm 0.1 inches and a repeatability of \pm 0.01 inches, additional leakage of less than 275 gallons (based on 2,750 gallons per inch) could be used to confirm the leak. Any substantial leakage could be confirmed within 48 to 72 hours using this method. Of course, if a leak were confirmed, the remaining liquid would be pumped back out of the SST.

In estimating the solids content of the tank, absolute accuracy is not required but precision from one estimate to the next is. Since the initial value is known, subsequent estimates will take into account the difference and not focus so much on the absolute volume. This knowledge will assist those making the estimates.

\subsubsection{Methods of Level Measurement}

Three current tools in use at the Hanford Site for in-tank liquid level measurement are described below.

\section{-Enraf Level Gauges}

The Enraf Nonius ATG 854 Level Gauge is a displacement type level gauge that has been in use in the Tank Farms for approximately two years. A displacer on a thin wire is lowered into the tank until it contacts the waste surface. At this point, some of the weight is displaced by the liquid or solid. When a preset amount of weight is displaced, the displacer is stopped and the level measured. The instrument raises or lowers the displacer to make up for changes in the weight displaced to update the level readings. The gauge is capable of compensating for crystal growth on the plummet and to changes in specific gravity of the waste. The Enraf Nonius gauge is replacing other level monitoring devices in the tank farms as existing instruments (e.g., FIC) fail. The instrument has a resolution of 
0.01 inches and is being evaluated to determine its' accuracy in use in the SSTs. If a solid surface is contacted, the level at that point only will be known so the evenness of the surface can affect the accuracy.

The gauge can also be utilized to determine the specific gravity of a liquid by locally placing the gauge in another mode. This requires the use of a local Field Interface Unit. In this mode, the displacer is lowered to a level determined by the local operator and the weight displaced determined. Since the volume of the displacer is known, the specific gravity of the displaced liquid can be determined. A possible source of error for this is crystal build up on the wire and displacer where the volume displaced is no longer known. A system to flush the wire and plummet is necessary to remedy this error and has been installed with the gauges on Hanford Site tanks. The vendor advertised accuracy for determining specific gravity is $\pm 5 \mathrm{~kg} / \mathrm{m}^{3}$ or better than \pm 0.5 percent for liquids with a specific gravity greater than water (White 1995).

Preliminary indications are that the Enraf level gauge as an accuracy of about \pm 0.1 inches with a level liquid surface (Cruse 1995). This corresponds to a volume of approximately \pm 275 gallons in a 75 -foot diameter tank. However, an action limit for liquid surface level changes in tanks requiring investigation for leaks has been set to the same level as the FIC gauge which is \pm 0.5 inches (Johnson 1995). Performance would decrease with a solid surface. Some degradation of level measurement performance would also be seen in a non-quiescent (e.g., during sluicing or mixer pump operation) tank due to the movement of the displacer. An Enraf gauge could be employed continuously during SST retrieval with the use of a stilling well, but it may be more beneficial to stop sluicing and pumping and allow the waste to settle prior to taking a measurement. If the sluice stream impacted the displacer directly, it would likely break the wire.

\section{- Food Instrument Corporation Level Gauge}

The Food Instrument Corporation (FIC) Level Gauge is a conductivity type level gauge that has been in use for a number of years in the Tank Farms as the primary automatic means of monitoring tank liquid surface level. A plummet on a steel tape is lowered automatically until it contacts the surface of the liquid completing an electrical circuit. The plummet then stops and a reading is taken automatically. At one-minute intervals, 
the plummet is raised until contact is broken and then lowered again to reread the level. This instrument does not work well with solid surfaces that are non-conductive. The gauge is no longer manufactured and is being replaced by the Enraf Nonius ATG 854 level gauge.

The FIC gauge itself is capable of an accuracy of \pm 0.03 inches and a repeatability of \pm 0.01 inches. However, after use in the tank farms and review of the data, a measurement precision of \pm 0.25 inches was empirically established. The specification limit for investigating possible tank leakage for FIC readings from tanks with a liquid surface waste then set at \pm 0.5 inches (Johnson 1995).

\section{- In Tank Drywell}

Currently, SSTs that do not have a liquid surface have their interstitial liquid level monitored using what is called a drywell van with a neutron probe which is lowered into an in tank drywell known as a Liquid Observation Well (LOW). A gamma probe scan may also be done upon request and acoustic probes have also been used in the past. The LOW is a drywell which extends to the tank bottom, is approximately three inches in inside diameter, and is normally constructed of fiberglass or Tefzel ${ }^{\mathrm{TM}}$. Determining the interstitial liquid level in this manner is labor intensive and requires interpretation of the data. Since interstitial liquid level is not required to perform mass balances during sluicing, the method is not considered further.

\subsubsection{External Leak Monitoring}

Due to the time frame for tank leakage to reach the detectors, the external methods are considered leak monitors as opposed to leak detectors.

\subsubsection{Neutron Logging of Drywells}

Neutron logging is a technique developed for borehole geophysical (or well) logging to determine the porosity and moisture content of the soil surrounding the borehole. A probe consisting of a neutron source and a thermal neutron detector is lowered down the borehole and the response of the neutron detector is recorded. The higher the water or organic content of the soil, the greater the response of the probe because hydrogen in the water/organic is nearly equal in mass to the neutron and, therefore, is efficient at slowing down (or thermalizing) the neutrons.

\begin{tabular}{|l|c|ll|}
\hline \hline ARES & $\begin{array}{c}\text { TM Tefzel is a trademark of E.I. du Pont de Nemours } \\
\text { \&osporamion }\end{array}$ & PAGE NUMBER & 26 \\
\hline \hline
\end{tabular}


Neutron logging can be performed in either a cased or uncased borehole. The only restriction would be to avoid use of neutron absorbing materials (such as borosilicate in some fiberglass). Various types of neutron sources and detectors can be utilized but will not be discussed further here.

On the Hanford Site, neutron logging in existing drywells located around SSTs is not normally performed, but could be utilized for external leak monitoring. Neutron scans are performed regularly in LOWs for determination of the interstitial liquid level in SSTs that do not have a liquid surface. Neutron logging capabilities are available on the Hanford Site from two new "drywell vans" and also from older drywell vans that will eventually be taken out of service.

The ability for neutron logging to identify and monitor a leak in the SSTs is dependent upon the size, rate, and location of the leak, location and number of drywells, the characteristics of the soil, and percentage of hydrogen in the leaked fluid (there are some inorganic liquids in the SSTs such as tributyl phosphate and carbon tetrachloride). Studies performed by Isaacson and Gasper in 1981 (cited in Johnson) indicated that a gamma probe in the SST drywells were capable of identifying and monitoring a leak of 1,375 gallons. Since the spacing of the drywells is large and the detection distance of the neutron probe is on the order of two to three feet (as opposed to about one foot for the gamma probe), it seems reasonable that this would be the approximate detection limit for the neutron probe as well. Based upon a maximum leak rate of $0.03 \mathrm{gal} / \mathrm{min}$ (Johnson), it would take approximately 32 days to determine whether a leak has occurred. Neutron logging in a drywell is generally not capable of determining the volume leaked unless other wells can be utilized to determine the size of the plume. The neutron logging system is not deployed on a continuous basis and would be an expensive technology to use repeatedly during an SST retrieval operation. In addition, the waste leaked needs to penetrate the soil to the location of the probe which results in a significant time delay to detection. Because the system cannot be used continuously and external soil features could readily reduce the capabilities of monitoring a leak, the neutron logging of drywells is not useful for leak detection.

\subsubsection{Passive Gamma Logging of Drywells}

Passive gamma logging is similar to neutron logging except gamma radiation that is naturally occurring or has been introduced into an area is detected. No neutron source is used to activate elements to produce gamma radiation as in active 
gamma logging. In this application for leak monitoring, the radionuclide content of the waste is used to provide indication of a leak. Gamma logging can be performed in either a cased or uncased borehole, but the use of thick casings of dense material (such as steel) will reduce the sensitivity of the system due to attenuation of the gamma radiation. On the Hanford Site, gamma logging of SST drywells is performed monthly for those tanks with no primary leak detection and upon request for other SSTs. Capabilities for gamma logging are maintained onsite.

Similar to the neutron probe, the ability of gamma logging to identify and monitor a leak in the SSTs is dependent upon the size, rate, location of the leak, location and number of drywells, the characteristics of the soil, and the content and type of gamma emitters in the leaked fluid. As stated above, it has been calculated that the gamma probe in an SST drywell has the ability to identify and monitor a leak of 1,375 gallons. However, this is based on the Ru-106 content of the waste. Ru-106 has a half-life of 367 days, and 15 years have elapsed since this calculation was performed. In this time, the Ru-106 concentration has decreased by a factor of 3.1E-05. Cs- 137 is the gamma emitter of highest concentration in most SSTs now, but it is also readily absorbed by the Hanford soil which retards its' migration and, hence, reduces the ability to detect it at a drywell. Another study by K.T. Key in 1977 (cited in Lewis) states that the gamma probe in a SST drywell can detect a 1,500 gallon leak. At a maximum leak rate of $0.03 \mathrm{gal} / \mathrm{min}$, it would take between 32 and 35 days to detect a leak using these estimates. Over time, the ability to detect a leak will decrease due to the decay of gamma emitters in the tank waste. Gamma logging in a drywell is generally not capable of determining the volume leaked unless other wells can be utilized to determine the size of the plume. The gamma logging system is not deployed on a continuous basis and would be an expensive technology to use repeatedly during an SST retrieval operation and suffers from the same time delay to detection as the neutron probe. For the same reasons as the neutron probe, the use of a gamma probe in SST drywell logging is considered leak monitoring and not leak detection.

\subsubsection{Leak Detection Pits}

In the four tanks in the AX Tank Farm, a leak detection pit is also provided. The pit is designed to collect any leakage from channels in the tank concrete foundation. A radiation probe, a level monitor, and specific gravity instrument are located in the bottom of the pit to detect tank leakage. No assessment of the 
capabilities of this system have been made, but much smaller leak volumes should be detectable which would also improve the time to leak detection. This system could likely be considered a leak detector although it may be possible for a leak to occur in a location where the liquid does not flow to the leak detection pit.

\subsubsection{Candidate Leak Detection Technology}

This section provides information on proposed leak detection technologies that may be able to be developed further for use as leak detection techniques for the SSTs.

\section{- Electrical Resistivity Tomography}

Electrical Resistivity Tomography (ERT) is an external leak detection/monitoring technology that measures the $\mathrm{DC}$ resistivity of a subsurface area or volume between an array of probe pairs and then develops a 2-D or 3-D plot of results. Because most minerals are insulators, current in the soil is typically conducted by pore liquids. If an array of electrodes were positioned around a SST and a leak developed, a decrease in resistivity between electrodes in this current path would be seen. The electrodes need to be in intimate electrical contact with the soil.

Field experiments conducted at the Hanford Site (cited in Lewis) using a pilotscale tank indicated the capability to detect a 100 gallon (seven gal/hr) leak of $0.08 \mathrm{M}$ sodium chloride solution. In this experiment, electrodes were placed into 16 wells that ringed the pilot-scale tank. The wells extended to 35 feet below the tank bottom and electrodes were spaced vertically every five feet. Current data collection and processing capabilities allow for the production of 2-D plots every 20 minutes and 3-D plots every six days. The software used in this test is reportedly being rewritten to reduce the $3-\mathrm{D}$ processing time to one day.

ERT seems to offer much promise, but further testing needs to be performed to determine the effects of electrical noise in the tank farms, effects of multiple tank geometry, and the effects of large or high conductivity leaks that could saturate the system leading to no resolution. ERT could be deployed on a continuous basis during SST retrieval. ERT at the present would likely be considered a leak monitor but could develop into a leak detector as the technology improves.

\section{- Time Domain Reflectometry}

Time Domain Reflectometry (TDR) is a technology that has been utilized to determine soil moisture content remotely by measuring the dielectric constant $\left(\mathrm{K}_{\mathrm{a}}\right)$ of the soil. In this application, it would be used to monitor for soil moisture as an 
external leak monitor. The dielectric constant of dry soil is typically three to six, while the dielectric constant of water is typically 79 to 82 (depending on temperature). Since water dominates the dielectric constant of the two, it can be used to determine its' percentage present even in varying soils. Information of the dielectric constant of tank liquids is not well known but will be high due to the presence of water and salts.

TDR measures reflected voltage with time and was originally designed to locate faults and defects in metallic cables. In this application for a known velocity of propagation, the time of travel also represents the distance traveled by the reflected signal (Look 1992). Knowing the dielectric constant of the cable allows technicians to find the distance to a fault from the equation:

$$
K_{a}=\left(\frac{c t}{L}\right)^{2}
$$

Where: $\quad K_{a}=$ apparent dielectric constant

$c=$ velocity of light in a vacuum

$L=$ path length in a material

$t=$ travel time

To determine the dielectric constant of a soil, a probe at the end of a coaxial cable is inserted in the soil (waste). The reflected response from the probe will be seen as a discontinuity and since the length of the probe is accurately known, the dielectric constant of the soil can then be accurately determined and the percent moisture obtained. An increase in percent moisture would then be indicative of a tank leak.

The capability of TDR to detect a leak in the SSTs is dependent upon the size, rate, location of the leak, location and number of TDR probes, and the characteristics of the soil. Conventional TDR can detect changes in moisture content as low as one percent void fraction water. The estimated detection radius for a TDR probe is one foot at best (Lewis) so a large number of probes would be needed to assure detection. The probe must be in intimate contact with the soil. At best we could assume a capability to identify and monitor leaks of the same size as the gamma probe in a drywell if a similar number of probes are used. TDR could be deployed continuously during SST retrieval. TDR is considered a leak monitor and not a leak detector. 


\section{-Tracer Tightness Testing}

Tracer tightness testing is performed by mixing an inert, volatile chemical concentrate (i.e., a tracer) with the wastes in a tank. The tracer must be selected so that it is compatible with the wastes but unique to the tank contents and outside environment. If a leak occurs, the tracer diffuses from the liquid and is detected via soil gas monitoring probes. Typically, a high resolution gas chromatograph is used for detection of the tracer gas. In some instances, it may be necessary to take a vapor sample that would then be delivered to a lab for analysis.

Tracer Research Corporation is cited (Lewis) as successfully conducting tracer tightness tests on underground storage tanks at sites primarily related to the petroleum industry. A detection sensitivity of $0.05 \mathrm{gal} / \mathrm{hr}$ is routinely achieved, although leaks as small as $0.00005 \mathrm{gal} / \mathrm{hr}$ can theoretically be detected. However, several difficulties arise with this technique for Hanford SSTs.

- Even though the tracer is highly volatile it will be difficult if not impossible to get the tracer evenly mixed with the non-homogeneous and mostly solid waste of the Hanford SSTs. If the tracer were added to the sluicing water, this problem would be minimized. However, mixing of the sluice water with existing drainable liquids is not assured.

- Because the tracer is highly volatile it will exist in the vapor space of the tank as well. Sixty-seven of the SSTs are assumed leakers and even if no liquid is lost it is possible for the tracer vapor to exit the tank and be detected giving a false positive leak indication. In addition, the dome of the SSTs are not steel lined so it would also be possible for the vapor to exit via cracks and micro-cracks in the concrete tank dome.

- All chemicals undergo radiolysis in the high gamma radiation of the SSTs. Over time the tracer would have to be replenished, or lower leak detection levels would result.

Because of these three reasons, tracer tightness testing would not be likely to work in Hanford SSTs. If it did prove out, the small detection volumes could improve the indication time frame to the point where this method would be considered leak detection. 


\section{- Hydrostatic Tank Gauging}

Hydrostatic Tank Gauging (HTG) is another means of providing information to perform a mass balance on the tank contents to determine whether a leak has occurred. HTG involves the use of three high accuracy pressure transducers. Two are deployed near the bottom of the tank and one in the vapor space at the top of the tank. Knowing the distance between the two pressure transducers at the bottom of the tank allows for determination of the average specific gravity of the fluid. The total pressure on the bottom transducer, minus the vapor pressure, is then used to determine the hydrostatic head which can then be related to level or mass when the average specific gravity is known. HTG is a technology that has been available for use, and there are commercially available systems that are accurate to within 0.02 to 0.03 inches of level over narrow ranges.

Another HTG concept that has been used in Hanford SSTs is the use of bubblers where pressure transmitters would be located outside the tank and the pressures are determined by slowly bubbling air out through tubes located at the same locations described for the HTG transducer system. While this method has the advantage of locating the electronics outside the tank, it would likely be difficult to get the air to bubble out smoothly in waste that contains mostly solids. This will cause fluctuations in the level readings. Instrument air systems have also been historically unreliable in the Tank Farms, and air is not currently available at many of the SSTs. If instrument air is lost, the bubbler tubes will likely become clogged as past experience indicates and would need to be flushed with water or cleaned out mechanically which is undesirable in an isolated tank. Existing bubbler systems in the SSTs only have an accuracy of \pm 2.7 inches, but this could easily be improved with the use of updated pressure transmitters. Existing bubbler systems also use a water drip system to reduce to chances of being clogged with saltcake. These bubblers were used in conjunction with the salt well pumping system for level indication of liquids in the salt well screen.

As stated above it is possible to measure the hydrostatic pressure to within 0.02 to 0.03 inches of water over a narrow 10 - to 15 -inch range in a quiescent tank. Over the full range of approximately 400 inches, this accuracy would be reduced to \pm 0.8 inches or 2,100 gallons in a 75-foot diameter tank. In a Hanford SST during sluicing, there are additional problems due to the non-homogeneity of the waste and the amount of solids present. In tanks with a hard saltcake on top, it is possible to add water that will not diffuse down and come in contact with the interstitial liquid in the bottom of the tank and thereby exerting no hydrostatic head on the system. HTG could be employed continuously during SST retrieval, 
but as in the case with the Enraf gauge, it may be more beneficial to stop sluicing and pumping and allow the waste to settle prior to taking a measurement.

\subsubsection{Summary and Conclusions}

As stated in the introduction, the term "leak detection" is not really appropriate and the technology that currently exists is more appropriately called "leak determination." New technologies should continue to be investigated to provide a true "detection" device, although none appear to offer significant near-term opportunities.

As a discrete schedule of tanks to be retrieved by the ISSTRS is developed, selection of which leak detection system to utilize will occur on a tank-specific basis. The selection must depend on the allowable leakage value, quantity of waste, the retrieval results of other tanks in the farm, etc. Preliminary indications suggest that for most tanks, the mass balance technique is the most appropriate. Continuous evaluation of the selected leak detection method must occur to assure advances in technology or techniques are accounted for prior to selection of the final method. A summary table (Table 2) of the investigated technologies and the characteristics they were evaluated against is presented below. The remainder of this report assumes mass balance is utilized for leak detection because it is the only currently viable method; however, the limited sluicing process established previously is appropriate for all detection systems.

\subsection{OPERATIONAL RESPONSES}

\subsection{Existing Contamination}

As stated earlier, 67 SSTs are suspected of having leaked between 600,000 to 900,000 gallons of liquid since they were placed into operation. At least one leak has occurred in every SST farm. In addition to this leakage, past contamination control practices have left surface contamination in every SST farm as well. Current WHC plans are to complete pumping of all salt well liquid from the SSTs by 1999. At this time, it is estimated that there will be less than 1.45 million gallons of drainable liquid left in all of the SSTs. This is an average of less than 10,000 gallons of drainable liquid left in each tank. Because of this, there is a very low likelihood of a leak occurring during normal storage activities. However, in order to sluice the wastes from the tanks, a significant amount of liquid may be added to the tanks. Even so, because of the low historical leak rate of $0.03 \mathrm{gal} / \mathrm{min}$ discussed previously, the amount of time necessary to sluice a tank, and the use of MAL practices, it is unlikely that any leakage could approach the amount that has already leaked from the tanks. The planned minimum retrieval rate of the insoluble 


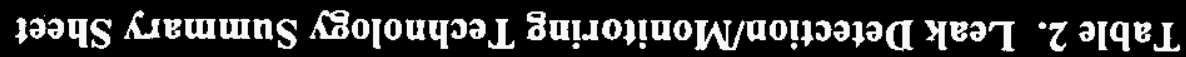

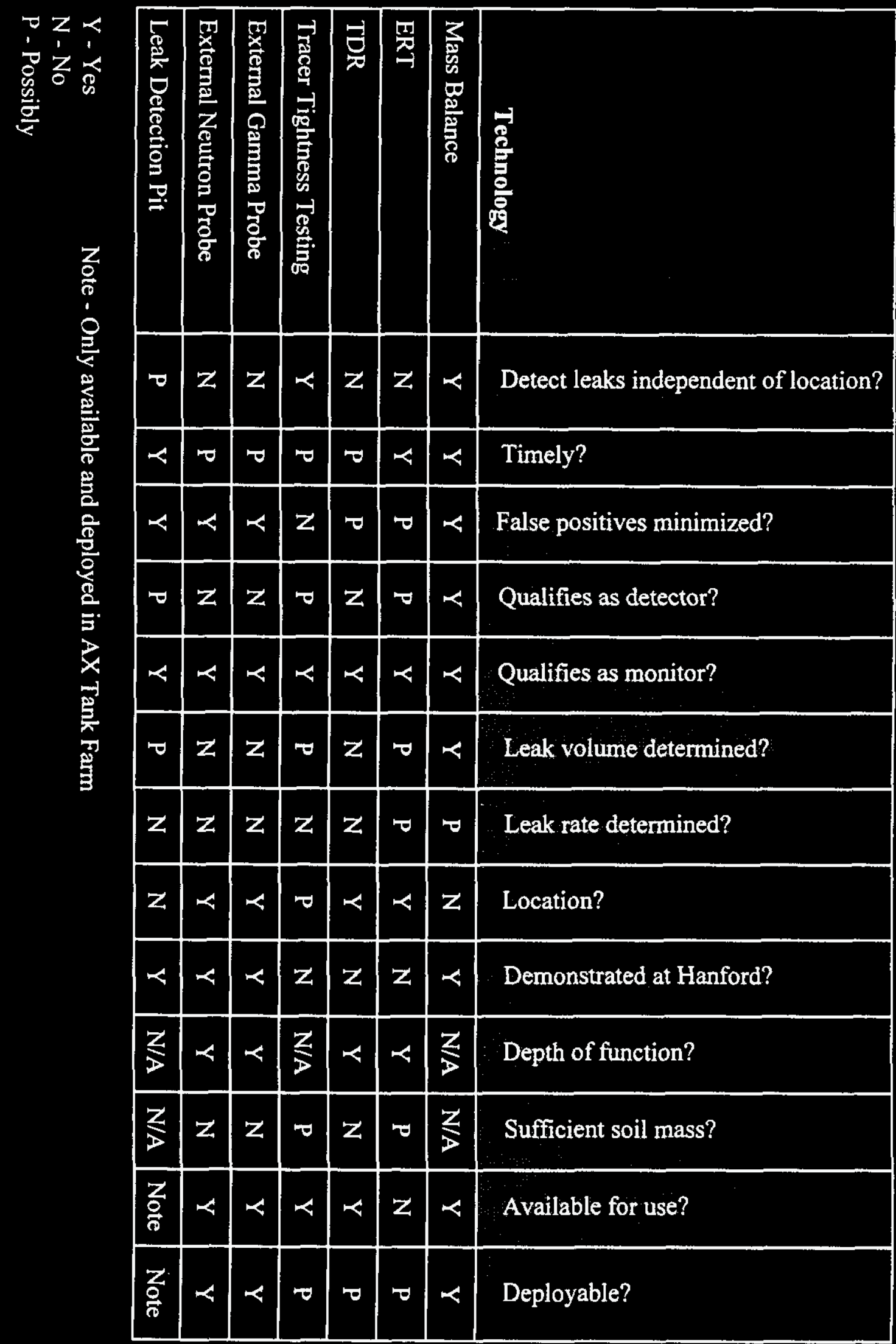


solids (sludge) in the SSTs is 16,900 gallons per day (Boomer 1993). Based on a maximum sludge volume of 446,000 gallons (T-111) and an average sludge volume of 81,200 gallons per tank, the maximum and average leaks are not expected to exceed 1,141 and 207 gallons respectfully. Both of these values are below all preliminary TLVs and below any likely detectable leakage.

\subsection{Retrieval Activities}

Three primary methods have been proposed for retrieval of wastes from the SSTs are:

- Mechanical methods such as a robotic arm with end effectors,

- Pneumatic methods such as a vacuum transfer system, and

- Hydraulic methods such as sluicing.

Based on life-cycle cost estimates (Boomer 1993), the first two methods are approximately four and one-half times more expensive than past practice and limited sluicing. Confined sluicing costs will be comparable to the mechanical and pneumatic costs due to the robotics necessary. This causes the estimated retrieval cost per SST to go from $\$ 2.6 \mathrm{M}$ for sluicing to $\$ 11.7 \mathrm{M}$ for mechanical or pneumatic retrieval. Therefore, based on costs and the relative risks associated with each method, sluicing represents the chosen method for the SST retrieval strategy. Mechanical and pneumatic retrieval may only be used where sluicing is ineffective (i.e., for the heel) or the risk of sluicing is too great (i.e., a tank known to have an extensive leak). Further, it is recommended that limited sluicing using the MAL approach be utilized to assure that the risk advantages over past practice sluicing and cost advantages over confined sluicing are realized.

Because any leakage from sluicing retrieval is unlikely to approach the amount of past leakage, a graded approach to leak response is proposed. This is consistent with the As Low As Reasonably Achievable (ALARA) concept in most respects in light of the potential costs associated with retrieval methods other than sluicing. Mechanical/pneumatic methods are slow, expensive, and will likely entail greater worker risk. If a small percentage of tank leakage relative to what is already there would be added by sluicing, the graded operational response approach presented in Section 5.3 seems to be a prudent path to follow. The existing contamination already needs to be addressed in the final closure plan for the SSTs and the additional contamination introduced will have a minimal impact of the closure plan, as long as any existing moisture from prior leakage does not increase the hydraulic conductivity in the vadose to a point where the closure plan might be affected. 


\subsection{Operational Response to SST Leaks}

Another means of leak mitigation is the operational response taken to an indication of a leak. Responses to leaks during sluicing retrieval should take into consideration the size of the leak relative to the allowable leakage value, the rate of the leak, whether the soil around the SST has been previously contaminated, the amount of waste remaining in the tank (i.e., time to complete sluicing), and whether any further leakage can be expected. Prior to retrieval, SSTs should be sorted by allowable leakage value, waste quantity, and past leakage to determine the extent of leak detection necessary and the type of retrieval method to be used. This information would also be used to determine an appropriate response to a suspected or confirmed tank leak.

The detailed process outlined in Appendix $\mathrm{C}$ is recommended for completion of immediate and follow-up actions in the event a SST leak is detected or suspected. The operational response recommended is a graded approach based on leak size (relative to the allowed leakage), the activity being performed, and the amount of waste left in the tank. Leak rate was not used as a discriminator due to the limitations of the proposed leak detection method. Over time the leak detection threshold should become lower due to improved technology while the preliminary TLV could become higher due to improved modeling and better waste characterization. Also, leak detection and monitoring capabilities will improve and ideally would improve to the point that retrieval operations could continue upon detection of a leak provided a predetermined leak threshold is not exceeded.

\subsection{Conclusions}

To best achieve the TWRS goal of MAL and leak mitigation during retrieval, the following actions are recommended:

- Identify the tanks for inclusion within the ISSTRS scope focusing on selection of sound, non-leaking tanks that can be readily sluiced,

- $\quad$ Refine waste data to develop final allowable leakage values for the selected tanks,

- Establish leakage-level limits using the guidelines detailed within this report,

- Complete detailed retrieval procedures utilizing the limited sluicing method. These procedures will be specific to each tank chosen,

- Approve the operational planned responses and have equipment available to support the actions identified within these responses, and

- Continue efforts to identify and develop better leak detection technologies.

These actions will provide assurance that the probabilities of leaks during retrieval are minimized, and assure that should leaks occur during SST retrieval, they can be managed to 
minimize any increased risk to the public. Other ISSTRS activities and design features which may or may not have been explicitly discussed in the rest of the report but merit consideration are listed below.

- Sluicing should proceed as quickly as possible once commenced to reduce the likelihood and size of potential leaks.

- ISSTRS equipment design should minimize the potential for down time during sluicing.

- All operational "surveillance" tools available should be utilized to the maximum extent practical for determining whether a leak is occurring (e.g., CCTV, flow rate, liquid level, etc.).

- New LDMM technologies should be utilized to the extent practical as they become available.

- Liquid level addition during sluicing should be minimized to the greatest extent practical.

- In using the mass balance method for leak detection, normal non-sluicing times should be used to visually assess sluicing effectiveness and to conduct visual solid level estimates. Stopping for level estimates will only slow down retrieval and increase the likelihood of a potential leak and is not recommended.

\subsection{IMPLEMENTATION}

In order to be prepared to support the SST retrieval, significant activities must be accomplished. These activities are best discussed in terms of those that must be accomplished to support start of SST retrieval (prior to 2001) and those that are ongoing during SST retrieval (after 2001).

\subsection{Activities Required Prior to 2001}

The following activities are required prior to 2001:

- A preliminary retrieval sequence which identifies the ISSTRS scope/schedule is being developed and must be finalized.

- Negotiations on the preliminary retrieval sequence and retrieval philosophy with involved stakeholders must occur. 
- The preliminary retrieval sequence scope must be reviewed with consideration given to the areas noted in this report.

- Detailed retrieval procedures (including operational responses) for retrieval must be prepared on a tank-by-tank basis. These tank-specific procedures detail the final allowable leakage values, the leak detection system most appropriate, and leak responses.

- Closure data must be factored into the procedures to assure that actions taken during retrieval support closure planning.

- A final selection of ISSTRS scope/sequence must be made and agreed upon by all stakeholders.

\subsection{Activities Required After 2001}

The following activities are required after 2001 :

- Evaluation of new and emerging leak detection methods should continue for those tanks where the allowable leakage values and minimum detectable leaks are not compatible.

- $\quad$ Allowable leakage values and procedures will continue to be updated based on characterization information and data gained during retrieval.

\subsection{Risks}

If implemented as described in this report, the leak detection methodology proposed minimizes the risk to the public and helps assure the success of the overall ISSTRS program. This conclusion is based on the data available to date and presented in this report. As better data is developed, the risk analysis which establishes allowable leakage values must continue to be updated to assure that the overall risk is maintained at acceptable levels.

\subsection{SUMMARY}

By carefully selecting the tanks for inclusion within ISSTRS and by implementing the limited sluicing concept discussed herein, the probability for leaks during retrieval is minimized. Based on historical leak rates, planned sluicing retrieval rates, and quantities of waste to be retrieved, the likelihood of a leak exceeding the minimum detection level or the allowable leakage value (should one occur) during limited sluicing retrieval is very low. (It was calculated that an 
average leak would likely not exceed 207 gallons, while a maximum leak would likely not exceed 1,141 gallons. This is compared to the smallest TLV of 2,700 gallons and current leak detection capabilities of approximately 5,570 to 8,270 gallons for mass balances.)

The limited sluicing retrieval process proposed for ISSTRS in this report will further mitigate the leak volume (and thus, the consequences) by retrieving in a structured sequence within each tank, applying the appropriate leak detection systems (currently mass balance technique), and by having detailed operational procedures and responses available to respond to any leak detected. The consequences of any leak which should occur can be controlled in this manner to assure that the minimum achievable leakage is maintained and that the risks to the worker, the public, and the environment are minimized.

\subsection{Recommendations}

In addition to the conclusions reached on the report objectives (Section 5.4), the following recommendations are made:

- $\quad$ Continue investigating improvements to leak detection technologies that may be needed for higher risk tanks (i.e., tanks with lower allowable leakage values and a higher probability of leaking).

- Perform risk assessment using improved consequence modeling (i.e., improve the baseline TLVs) and probability/rate distribution of leaks to determine whether SSTs are (still) considered sluicable or whether other means of retrieval should be employed.

- If possible, in light of all selection criteria for ISSTRS, tanks that represent a lower risk for gaining experience and improving techniques and procedures should be selected for retrieval first. Again, only sound (non-leaking) tanks should be selected for this effort.

\subsection{REFERENCES}

ARCO, "241-T-106 Tank Leak Investigation," ARH-2874, Atlantic Richfield Hanford Company, Richland, Washington, 1973.

Boomer, K.D., et al., Tank Waste Technical Options Report, WHC-EP-0616, Rev. 0, Westinghouse Hanford Company, Richland, Washington, March 1993. 
Brown, D. J., et al., "Status of Liquid Waste Leaked From the 241-T-106 Tank," RHO-ST-1, Rockwell Hanford Operations, Richland, Washington, 1979.

Cruse, J.M. et al., Functions and Requirements for Hanford Single-Shell Tank Leakage Detection and Monitoring, WHC-SD-WM-FRD-021, Rev. 0, Westinghouse Hanford Company, Richland, Washington, February 1995.

Droppo, et al., "Single-Shell Tank Constituent Rankings for Use in Preparing Waste Characterization Plans," PNL-7572, Battelle Pacific Northwest Laboratory, Richland, Washington, June 1991.

Estey, S.D., Mass Balance and Leak Detection Model, draft letter, Westinghouse Hanford Company, Richland, Washington, April 1995.

Freeman-Pollard, J.M., et al., Engineering Evaluation of the GAO-RCED-89-157, Tank 241-T106 Vadose Zinc Investigation. BHI-00061, Bechtel Hanford, Inc., Richland, Washington, 1994.

Hanlon, B.M., Waste Tank Summary Report for Month Ending June 30, 1995, WHC-EP-018287, Westinghouse Hanford Company, Richland, Washington, August 1995.

Johnson, M.G., Technical Basis for Leak Detection Surveillance of Waste Storage Tanks, WHCSD-WM-TI-573, Rev. 1, Westinghouse Hanford Company, Richland, Washington, February 1995.

Lewis, R.E., et al., A Survey and Description of Candidate Technologies to Support Single Shell Tank Waste Retrieval, Leak Detection, Monitoring, and Mitigation, PNL-10755, Battelle Pacific Northwest Laboratory, Richland, Washington, September 1995.

Look, Burt G., and Ian N. Reeves, The Application of Time Domain Reflectometry in Geotechnical Instrumentation, Geotechnical Testing Journal, vol. 15, no. 3, p 277-283, September 1992.

Treat, R.L., et al., Feasibility Study of Tank Leakage Mitigation Using Subsurface Barriers, WHC-SD-WM-ES-300, Rev. 0, Westinghouse Hanford Company, Richland Washington, 1994.

White, W.F., Record of Telephone Conversation B.D. Groth, 95RL1129, ARES Corporation, Richland, Washington, November 15, 1995. 


\subsection{BIBLIOGRAPHY}

Gibbons, P.W., et al., Review of Prior Single-Shell Tank Waste Retrieval Process Studies, WHCSD-WM-ES-252, Rev. 0, Westinghouse Hanford Company, Richland, Washington, 1993.

Isaacson, R.E. and K.A. Gasper, A Scientific Basis for Establishing Dry Well Monitoring Frequencies, RHO-ST-34, Rockwell Hanford Operations, Richland, Washington, December 1981.

Key, K.T., Nuclear Waste Tank and Pipeline External Leak Detection Systems, ARH-ST-127, Atlantic Richfield Hanford Company, Richland, Washington, 1977. 


\section{Appendix A}

\section{Mass Balance for Leak Detection}

In order to perform a mass balance to determine whether a leak has occurred in a SST during sluicing, it is necessary to define the initial conditions and determine what initial information and process instrumentation is available. The basis for this mass balance is the work performed by Estey (1995) with some simplifying assumptions. Because the initial conditions from tank to tank will vary, mass balance assumptions and techniques may also vary accordingly. The following example transfers waste from a SST to a DST. The SST has a layer of saltcake (soluble solids) over a layer of sludge (mostly insoluble solids). The DST has some insoluble solids in the bottom and dilute (unsaturated) supernate. The available instrumentation includes mass flow meters on the inlet and outlet waste transfer lines and makeup water lines, an EnrafNonius 854 ATG level gage on each tank, and thermocouple trees in each tank. The mass balance presented only covers these conditions which are fairly conservative. Different conditions may affect the assumptions made and the accuracies determined in Appendix B. Each tank retrieved must be evaluated to determine the mass balance capabilities prior to retrieval.

Initially, we need to determine the following from characterization and tank inventory reports.

1. Average density ( $\rho$ ) of insoluble solids (sludge) in the SST and DST.

2. Average density ( $\rho)$ of soluble solids (saltcake) in the SST. Soluble solids in DST are in solution.

3. Volume of insoluble solids, soluble solids, and supernate or interstitial liquid in both SST and DST.

4. Bulk temperature of the supernate in both SST and DST.

\section{Assumptions}

1. The density ( $\rho$ ) of the supernate changes with temperature the same as water. The density temperature correction factor will be called the DCF.

2. The density of the insoluble solids does not change appreciably with temperature.

3. Negligible amounts of sludge are removed until all the soluble saltcake is removed.

4. For this example assume both tanks are 75 feet in diameter. 
5. Evaporative losses are negligible. Note that in some cases this may not be valid and evaporative losses will require that they be determined.

\section{Initial Total Mass}

1. Definitions

$\begin{aligned} \rho= & \text { density (mass/gallon) } \\ V= & \text { volume (gallons) } \\ \operatorname{DCF}(T)= & \text { density temperature correction factor which is a function of } \\ & \text { temperature }(T) \\ L= & \text { level in inches } \\ m= & \text { mass }\end{aligned}$

\section{Subscripts}

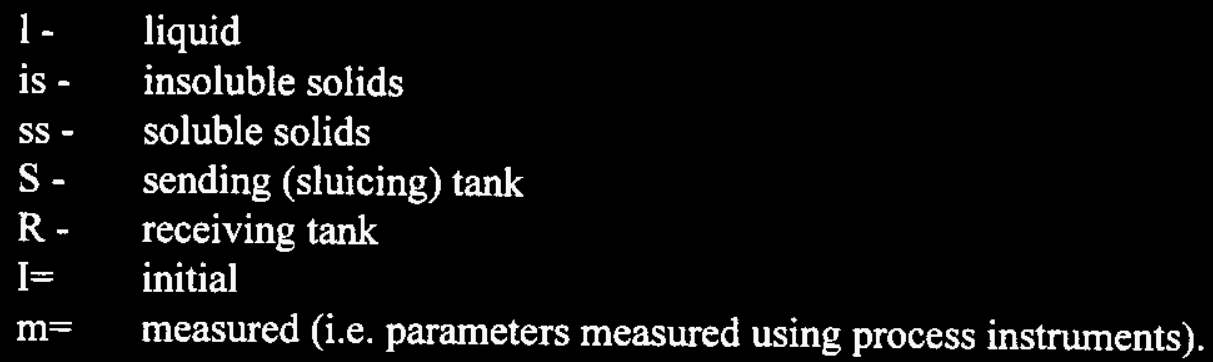

\section{Determine Initial Mass in System}

$$
m_{i}=\rho_{1, S, i} V_{l, S} \operatorname{DCF}\left(T_{i, S, m}\right)+\rho_{i s, S, i} V_{i s, S}+\rho_{s s, S, i} V_{s s, S}+\rho_{l, R, i} V_{l, R} D C F\left(T_{1, R m}\right)+\rho_{i s, R, i} V_{i s, \mathbb{R}}
$$

Note that the density correction factor is utilized here because it is assumed that the density from characterization data was determined at a standard temperature that is different from the current temperature in the tank. Density determinations during sluicing will be actual measurements that will not need to be compensated for temperature.

\section{Procedure}

After initial sluice and at the end of each batch sluice (typically every 16 hours) perform the following: 
1. Pump down sending tank completely (until pump losses suction head). Perform a visual estimate of solids remaining. Use all available measuring devices and landmarks. Assume all insoluble solids initially in sending tank are still there if any soluble saltcake is still present.

2. In this example, we will back check this calculation by refilling the tank above the solids. However, this step is not necessary if the possibility of leaks are a concern. If leaks are a concern, they can be mitigated by performing the procedure as quickly as possible, or by relying only on the estimate of solids left in the tank. As noted in the body of this document, any addition of liquid of this nature increases the potential for creating a leak and is not recommended in most circumstances.

Fill the sending tank back up with supernate or water until the solids are completely covered. Measure the mass of fluid added using the mass flowmeter. Measure the level and $S_{p} G$ of the supernate liquid now in the tank and back check the solids volume estimate as follows:

$$
\mathrm{V}_{\text {est }}=\mathrm{L}_{\mathrm{m}}\left(2750^{\mathrm{gal}} / \mathrm{in}_{\mathrm{in}}\right)-\mathrm{m}_{\text {added }} / \boldsymbol{p}_{1, \mathrm{~m}}
$$

Note that if there is a large volume of soluble solids still present there will be more error introduced. To mitigate this, minimize time between addition of supernate/water and measurement of level and $S_{p} G$. Note also $V_{s s}=V_{\text {est }}-V_{i s}$

3. Allow all lines to drain to either tank and measure liquid level, supernate $S_{p} G$, and average liquid temperature again. Perform mass balance. Once this step is complete, any liquids in the SST can be pumped back out.

4. Calculations

$$
\begin{aligned}
m_{i}+m_{\text {added }}= & \rho_{\mathrm{l}, \mathrm{S}, \mathrm{m}}\left[\mathrm{L}_{\mathrm{m}, \mathrm{S}}(2750 \mathrm{gal} / \mathrm{in})-\mathrm{V}_{\mathrm{ss}, \mathrm{S}, \mathrm{m}}-\mathrm{V}_{\mathrm{is}, \mathrm{S}, \mathrm{m}}\right]+\rho_{\mathrm{is}, \mathrm{S}, \mathrm{i}} \mathrm{V}_{\mathrm{is}, \mathrm{S}, \mathrm{m}}+\rho_{\mathrm{ss}, \mathrm{S}, \mathrm{i}} \mathrm{V}_{\mathrm{ss}, \mathrm{S}, \mathrm{m}}+ \\
& \rho_{\mathrm{l}, \mathrm{R}, \mathrm{m}}\left[\mathrm{L}_{\mathrm{m}, \mathrm{R}}\left(2750 \mathrm{gal} / \mathrm{in}-\mathrm{V}_{\mathrm{is}, \mathrm{R}, \mathrm{i}}\right]+\rho_{\mathrm{is}, \mathrm{R}, \mathrm{i}} \mathrm{V}_{\mathrm{is}, \mathrm{R}, \mathrm{i}}\right.
\end{aligned}
$$

Once all of the soluble solids are transferred, the equation will change as follows:

$$
\begin{aligned}
& m_{i}+m_{a d d e d}=\rho_{l, S, m}\left[L_{m, S}(2750 \mathrm{gal} / \text { in })-V_{s s, S, m}-V_{i s, S, m}\right]+\rho_{i s, S, i} V_{i s, S, m}+\rho_{l, R, m}\left[L_{m, R}(2750 g a l / i n)-V_{i s, R, i}\right. \\
& \left.-\left(V_{i s, S, i}-V_{i s, S, m}\right)\right]+\rho_{i s, R, i} V_{i s, R, i}+\rho_{i s, s, i}\left(V_{i s, S, i}-V_{i s, S, m}\right)
\end{aligned}
$$

which simplifies to: 


$$
\begin{aligned}
m_{i}+m_{\text {added }}= & \rho_{1, S, m}\left[L_{m, S}(2750 \mathrm{gal} / \mathrm{in})-\mathrm{V}_{\mathrm{is}, \mathrm{S}, \mathrm{m}}\right]+\rho_{\mathrm{is}, \mathrm{S}, \mathrm{i}} \mathrm{V}_{\mathrm{is}, \mathrm{S}, \mathrm{i}}+\rho_{\mathrm{l}, \mathrm{R}, \mathrm{m}}\left[\mathrm{L}_{\mathrm{m}, \mathrm{R}}(2750 \mathrm{gal} / \mathrm{in})-\mathrm{V}_{\mathrm{is}, \mathrm{R}, \mathrm{i}}-\left(\mathrm{V}_{\mathrm{is}, \mathrm{S}, \mathrm{i}}-\right.\right. \\
& \left.\left.\mathrm{V}_{\mathrm{is}, \mathrm{S}, \mathrm{m}}\right)\right]+\rho_{\mathrm{is}, \mathrm{R}, \mathrm{i}} \mathrm{V}_{\mathrm{is}, \mathrm{R}, \mathrm{i}}
\end{aligned}
$$

If the initial mass plus the mass added differs from the mass calculated from the right hand equations by an amount greater than the accuracy with which the mass can be calculated, then a leak should be suspected. The accuracy will be a function of the instrumentation used and is addressed in Appendix B.

Note that these equations could be written in a form where it could quickly be determined whether the measured process variable (level) is within the expected range. The preferred methodology would utilize a computer with initial data already entered. Then all that is necessary would be to input the data and review the results. 


\section{Appendix B \\ Mass Balance Accuracy}

The Enraf-Nonius Level Gage can measure density to an accuracy of $\pm 5 \mathrm{~kg} / \mathrm{m}^{3}$. If we assume the $S_{p} G$ has a lowest value 1.0 , this would indicate a worst case accuracy of $\pm 0.50 \%$.

Repeatability is unknown.

The Enraf-Nonius Level Gage can measure level with an accuracy of better than \pm 0.1 inches. Repeatability may be as high as \pm 0.01 inches.

The accuracy of type $\mathrm{J} \& \mathrm{~K}$ thermocouples currently in use in the tanks is only $\pm 4^{\circ} \mathrm{F}$, but the repeatability over the short times between temperature measurements should be much better. Using $140^{\circ} \mathrm{F}$ as a nominal temperature, the error in DCF would be:

$$
\left[\left(983.200 \mathrm{~kg} / \mathrm{m}^{3}-982.005 \mathrm{~kg} / \mathrm{m}^{3}\right) /\left(982.005 \mathrm{~kg} / \mathrm{m}^{3}\right)\right] \times 100 \%=0.12 \%
$$

At higher temperatures, the error is slightly more, and at lower temperatures slightly less.

To put these errors in volume context, we must make some assumptions about volumes to be retrieved. If we assume a typical retrieval is 200,000 gallons of solids retrieved using 600,000 gallons of supernate (a good average) the errors would be:

$\pm[(600,000 \mathrm{gal})(0.005)+(600,000 \mathrm{gal})(0.0012)+(0.1$ inch $)(2750)]= \pm 4,270$ gallons

This total volume accuracy of $\pm 4,270$ gallons comes primarily from the $\pm 3,000$ gallon accuracy of the Enraf-Nonius gage to measure density. In order to improve this accuracy, it is recommended that a Micro Motion CMF 300 in line mass flow meter be installed in the inlet sluicing line and the outlet pump line. This instrument has the capability to measure density with an accuracy of $\pm 0.05 \%$ and a repeatability of $\pm 0.02 \%$. This would improve the volume accuracy associated with density measurement to \pm 300 gallons and the total volume accuracy to $\pm 1,570$ gallons.

This total volume accuracy must be added to the error associated with a visual estimate of the solids. It should be possible to estimate the solids level to within $\pm 1.0 \mathrm{inch}$, and waste surface irregularities (high and low spots) should average out. Because there will be some slope to the solids, an accuracy of $\pm 4,000$ gallons for this estimate is calculated. Since the amount of solids removed per day will not likely exceed the minimum of 16,900 gallons by much, the accuracy of $\pm 4,000$ gallons for the visual estimate also seems reasonable because the difference from the last visual estimate is all that is required. Thus, the overall accuracy would be $\pm 5,570$ gallons to 
$\pm 8,270$ gallons if the Enraf-Nonius gage is used to measure density.

Note also that absolute accuracies were used, whereas the repeatability is what would be the difference from one measurement to the next. The actual volume of wastes being retrieved and the types of waste will also figure greatly in the accuracy (i.e., minimum detectable leak). 


\section{Appendix C \\ ISSTRS Operational Leak Response}

\subsection{INTRODUCTION}

This appendix contains a description of a graded operational response to a confirmed or suspected SST leak. The graded approach is based on the leak size (relative to the allowable leakage value), leak location, and the amount of waste left in the tank. This operational response is based on the gross leak detection capabilities of the mass balance method. As leak detection capabilities improve, more refined operational responses can also be developed.

\subsection{LEAK LOCATIONS}

The following are definitions of leak locations used in the graded operational response.

- Tank Leak - Leakage that occurs during sluicing directly from a tank.

- Transfer Leak - This refers to a leak occurring in a transfer line during sluicing as opposed to a leak through the tank shell. This specifically refers to a leak to the environment and not to a leak into a containment such as a valve pit or a leak in the primary pipe of an encased pipe.

\subsection{ISSTRS LEAK RESPONSE}

Section 3.1 contains five actions to be performed immediately upon detection of a leak. Section 3.2 then contains three follow-up actions of which only one will be performed depending on the circumstances.

\subsection{Initial Detection of Leak Immediate Actions}

- Stop all addition of liquid to the tank, if applicable

- Stop retrieval pump, if running, until leak is confirmed to not be in transfer line.

- If retrieval pump is installed and it is quickly confirmed that the leak is not in the transfer line, then pump tank contents as low as possible (i.e., until pump suction 
is lost). If leak is in a transfer line, establish an alternate route before pumping resumes.

- Confirm leak or no leak through review of available indications such as mass balances, leak detection drywells, leak detection laterals, leak detection pits, or recently installed leak detection devices. In some cases, liquid could be added back to the tank to perform a static mass balance as described in the main body of this report (see Section 4.3.1).

- Determine to the maximum extent possible the size and location of leak through use of leak detection drywell and/or lateral scans, mass balances, and visual inspections using CCTV. Determine to the maximum extent possible the amount of drainable liquid remaining and the amount of solids remaining.

\subsection{Follow-up Actions}

- If leakage is determined to be greater than the allowable leakage value, all sluicing operations on that tank will be halted after all pumpable liquid is removed, the tank placed in a stable condition, and another means of retrieval employed (i.e., under another program).

- If leakage is less than the allowable leakage value and the volume of remaining waste is less than the difference between the allowable leakage value and the volume of waste leaked from the tank, then sluicing may proceed to remove the remaining waste.

- If the leakage is less than the allowable leakage value, and the volume of remaining waste is greater than the difference between the allowable leakage value and the volume of waste leaked from the tank, then sluicing may resume only if it is determined there is a high probability of retrieving the remaining waste before the allowable leakage value is exceeded. If it is not highly probable the waste can be retrieved before the allowable leakage value is exceeded, then sluicing will be halted after removal of all pumpable liquids, the tank placed in a stable condition, and another method of waste retrieval employed (i.e., under another program).

In determining whether the remaining waste can be retrieved without exceeding the allowable leakage value, consider whether the leak rate can be determined, and the location of the leak and whether it can be worked around. 


\section{DISTRIBUTION SHEET}

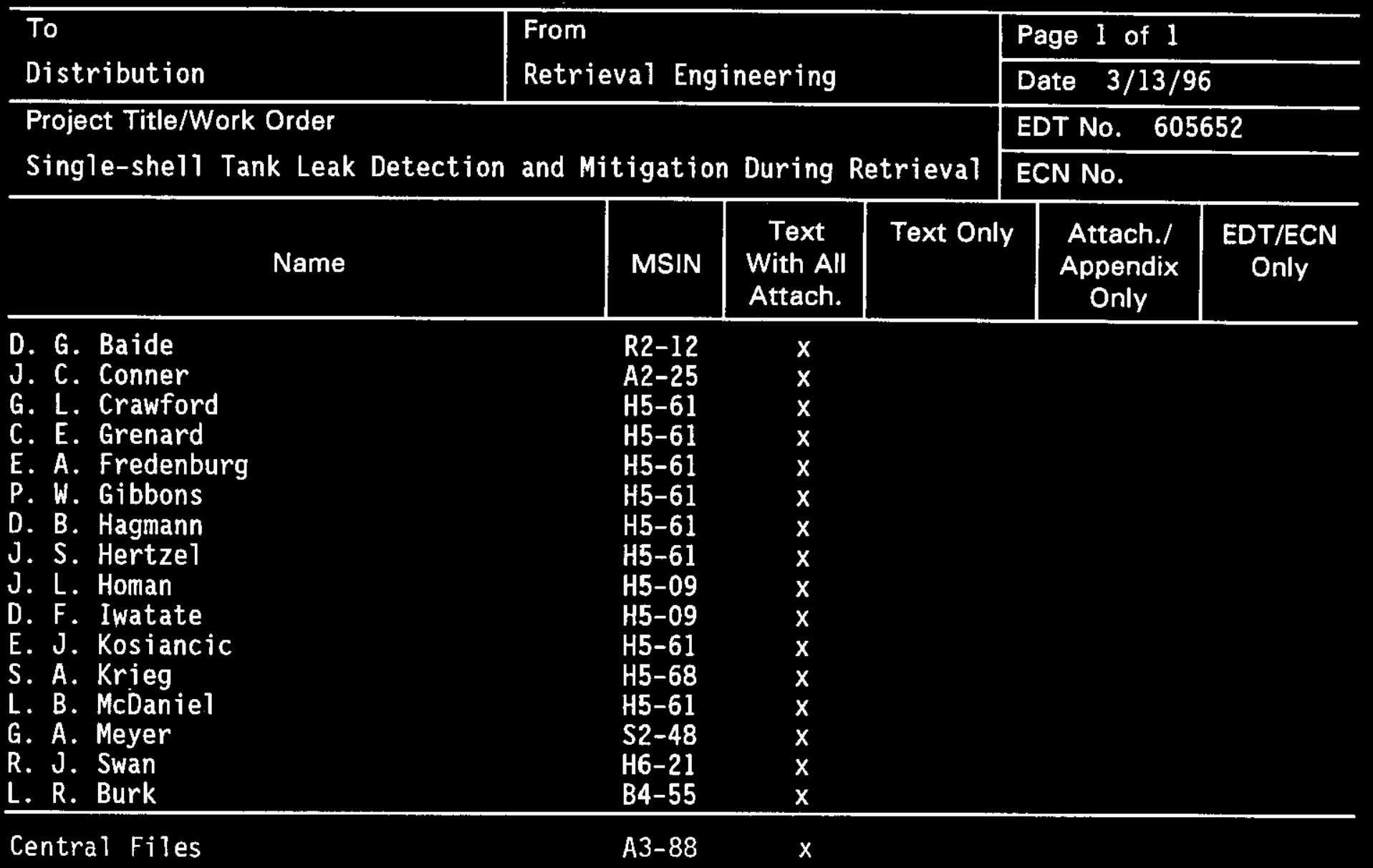

